Elsevier

BRR 90065

\title{
A review of the organization and evolution of motoneurons innervating the axial musculature of vertebrates
}

\author{
Joseph R. Fetcho \\ Division of Biological Sciences, The University of Michigan, Ann Arbor, MI 48109 (U.S.A.)
}

(Accepted 23 December 1986)

Key words: Motoneuron; Axial musculature; Myomere; Medial motor column; Spinal nerve; Vertebrate

\section{CONTENTS}

1. Introduction

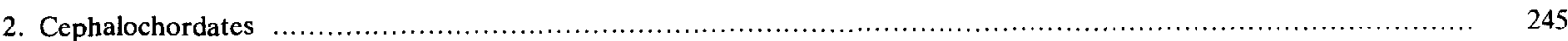

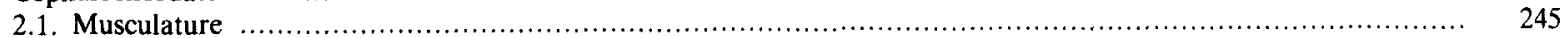

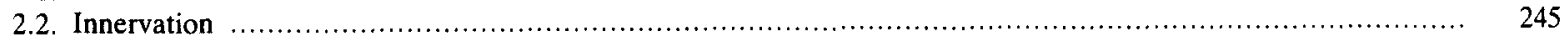

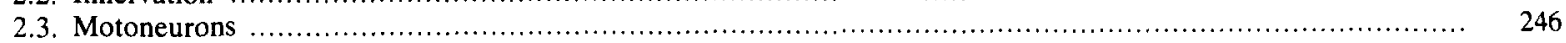

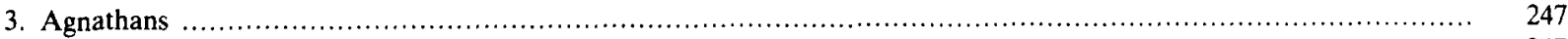

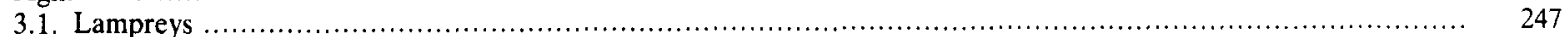

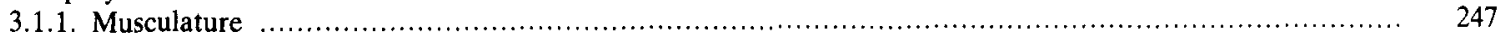

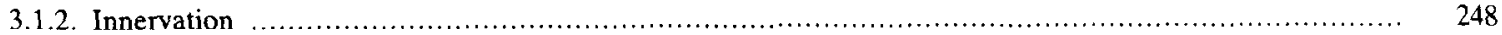

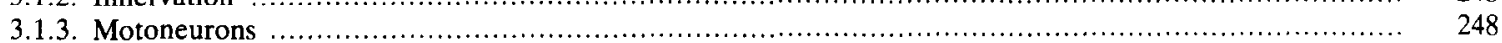

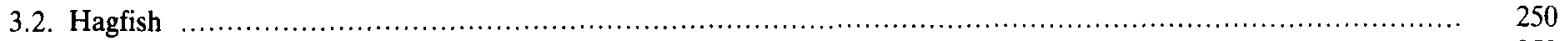

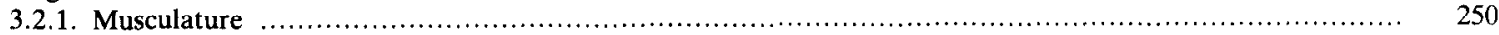

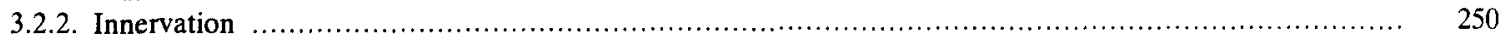

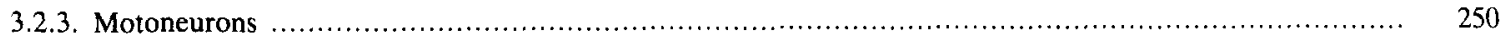

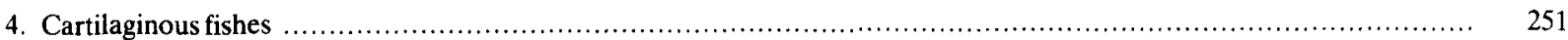

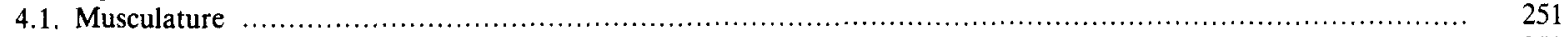

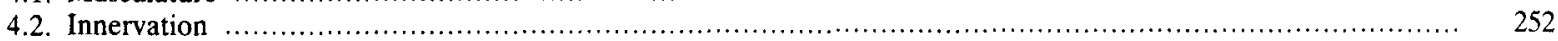

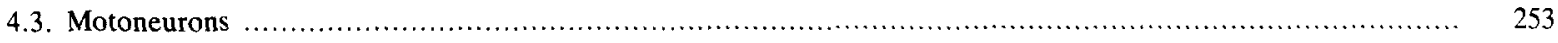

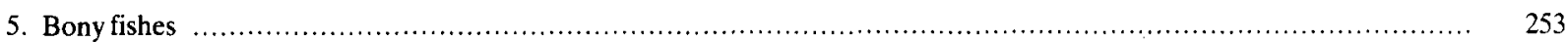

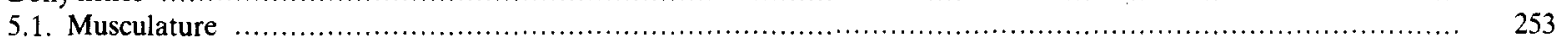

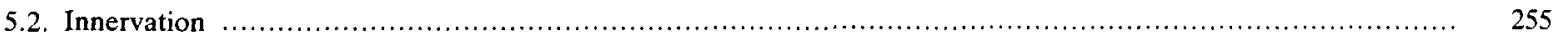

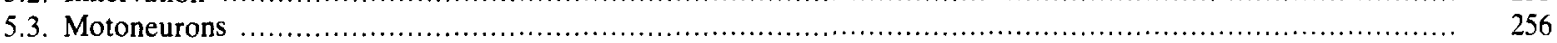

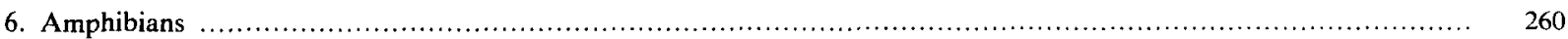

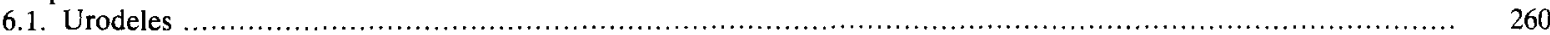

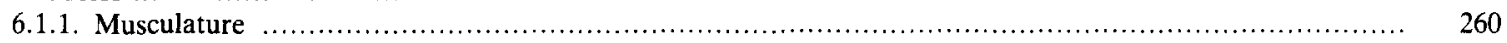

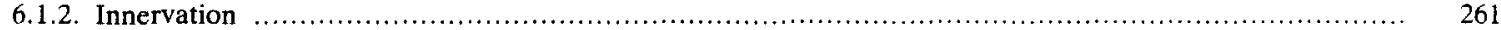

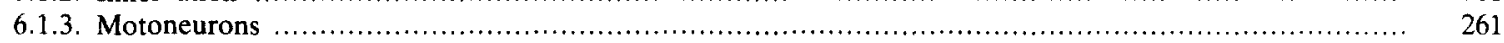

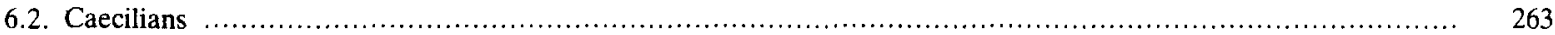

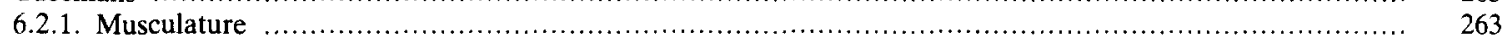

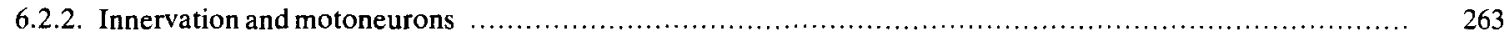

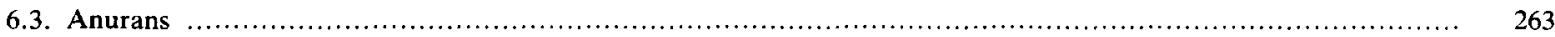

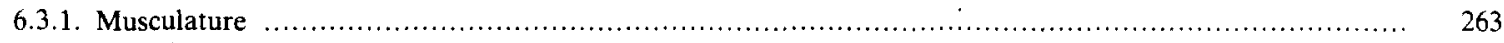

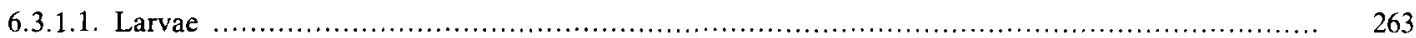

Correspondence: J.R. Fetcho. Present address: Div. of Neurobiology, 313 Cary Hall, State University of New York at Buffalo, Buffalo, NY 14214, U.S.A.

0165-0173/87/\$03.50 (C) 1987 Elsevier Science Publishers B.V. (Biomedical Division) 


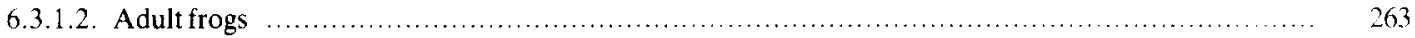

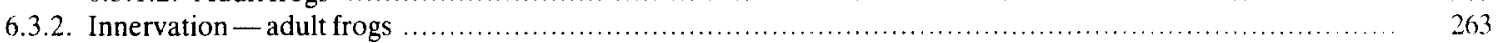

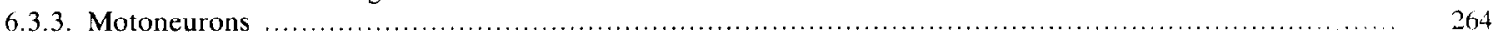

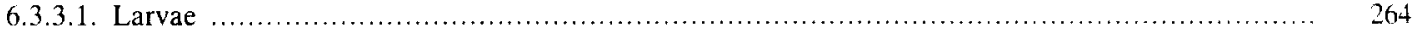

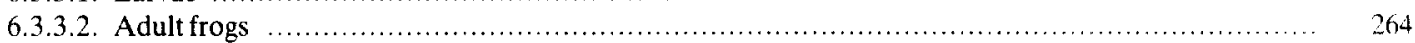

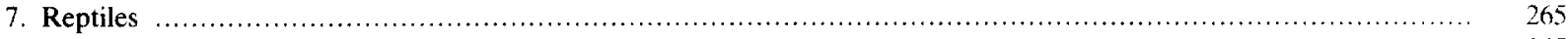

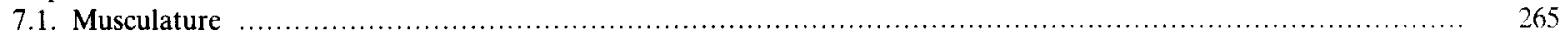

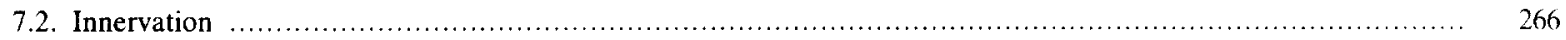

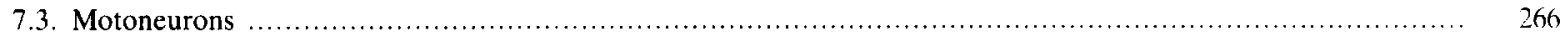

8. Birds

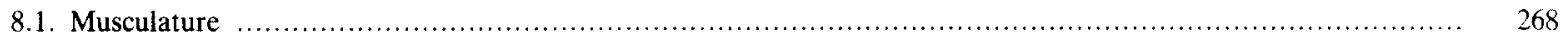

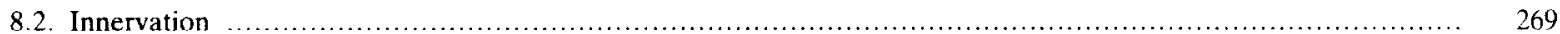

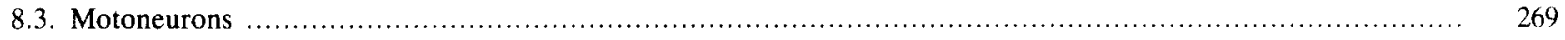

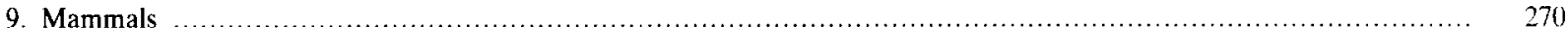

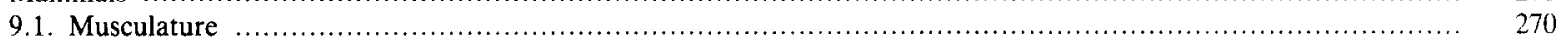

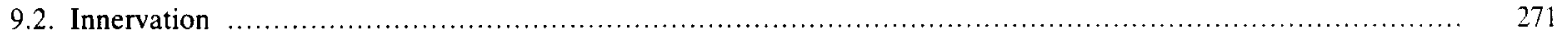

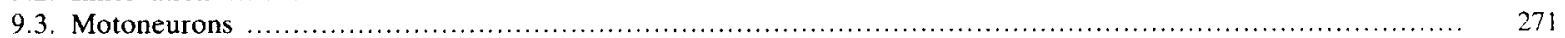

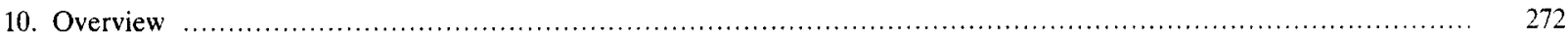

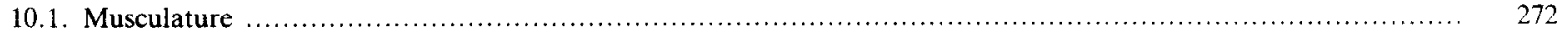

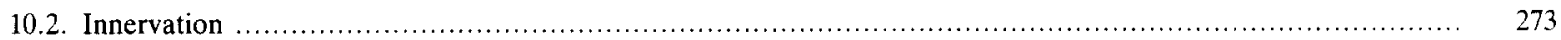

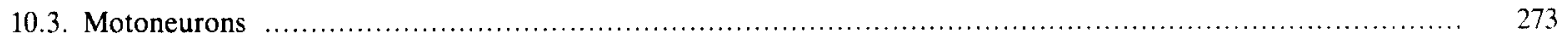

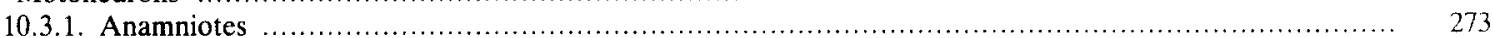

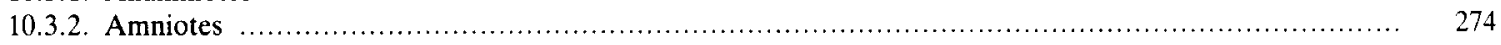

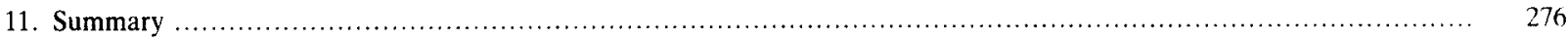

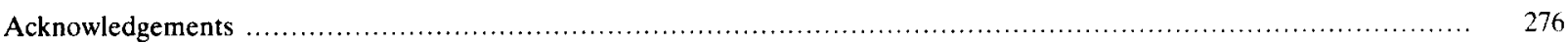

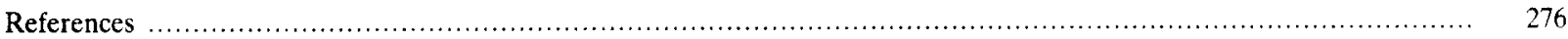

\section{INTRODUCTION}

A segmental or myomeric arrangement of axial muscles forms the embryonic and phylogenetic bases for the development of nearly all of the motor systems in vertebrates. Derivatives of a relatively simple, primitive myomeric musculature form limb muscles, eye muscles, complex arrays of axial muscles, and perhaps even the branchiomeric muscles associated with the visceral arches and jaws ${ }^{96}$. The striking diversity in the differentiation of the myotomes has been evident for nearly a century. This diversity is certainly in part responsible for an associated diversity in locomotor mechanics among vertebrates. However, motor systems probably have not evolved solely through modifications of the musculature without concomitant changes in the central nervous system (CNS) controlling the muscles. Until the advent of modern neuroanatomical techniques the relationship between the organization of the musculature and the organization of the CNS was difficult to obtain. Consequently, relatively few species were stud- ied, and modifications of the CNS associated with the differentiation of myotomal musculature were difficult to recognize. Fortunately, more studies are now relating the central and peripheral parts of motor systems; in particular, many relate the organization of the motoneurons within the motor columns to the organization of the muscles they innervate. These studies are beginning to provide new and important insight into the organization and evolution of motor systems, and they form the focus of this review.

I deal only with studies of the axial musculature and the motoneurons in the medial motor column which innervate it (the derivatives of axial musculature that form the extraocular and appendicular muscles are not considered). The medial motor column is an especially appropriate place to examine the evolution of motor systems, both because of the importance of axial musculature as the ancestral musculature among vertebrates, and because there is as much, if not more, diversity in the arrangements of axial muscles among vertebrates than in any other motor system. Consequently, substantially different 
musculo-skeletal systems that are derived from a common ancestor can be compared to determine whether modifications of the musculature are associated with differences in the motor columns.

I begin with an account of the motor organization in the cephalochordates, the closest living relatives of the vertebrates. Then the musculature and motor columns of agnathans, cartilaginous fishes, bony fishes, amphibians, reptiles, birds and mammals are considered. For each group of vertebrates, the organization of the musculature, the peripheral nerves, and the motoneurons are considered in sequence. I conclude with a more speculative section in which I consider apparent evolutionary trends, suggest what these trends tell us about the organization and evolution of motor systems, and point out where further work is necessary to evaluate the hypotheses that emerge from recent work.

\section{CEPHALOCHORDATES}

The cephalochordates have some features of the motor organization found in most anamniotic vertebrates. These include a myomeric organization of musculature, functionally different superficial and deep fiber types, and comparable populations of motoneurons. Because of these similarities, I begin with an account of the arrangement of the musculature and motor column in these close relatives of vertebrates.

\subsection{Musculature}

The cephalochordates are the most primitive extant group of chordates having a segmental organization of axial musculature ${ }^{9,12}$. In Branchiostoma (Amphioxus) the axial musculature is formed by a series of $\mathrm{V}$-shaped myomeres with the apex of the $\mathrm{V}$ pointing rostrally. Each of the myomeres consists of a stack of horizontal, shcet-like, muscle fibers which extend from myoseptum to myoseptum ${ }^{50}$. The muscle fibers are divided into two major types shown in Fig. 1. The deep fibers, which form the first type, span the mediolateral extent of the myomere, and contain regularly arranged, densely packed myofibrils. The superficial fibers form the second type. They extend from the lateral surface of the myomere only a short distance medially, ending about one-fifteenth of the distance in toward the medial edge of

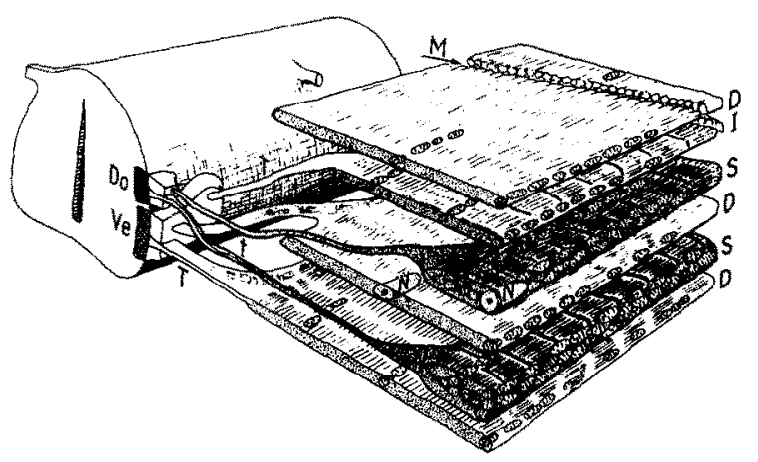

Fig. 1. Organization of the musculature and its relationship to the spinal cord in Branchiostoma. The superficial muscle fibers (S) send processes (t) to a dorsal compartment (Do) of the spinal cord while the deep (D) and intermediate fibers (I) send processes ( $\mathrm{T}$ ) to a ventral compartment (Ve). M, myoseptum; $\mathrm{N}$, nuclei. Reproduced (ref. 50) with permission of author and Springer Verlag.

the myomere. They have a more irregular array of myofibrils than the deep fibers, contain a larger number of mitochondria, more glycogen, and stain more strongly for succinic dehydrogenase ${ }^{50}$. Both fiber types are distributed throughout the dorsoventral extent of the myomeres in a ratio of about one superficial fiber to every 3 deep. There may also be a separate, intermediate fiber type, although Flood ${ }^{50}$ was not certain that this type was distinct from the other two.

\subsection{Innervation}

Prior to 1966 the pattern of innervation of the muscle fibers in Branchiostoma was unclear. Structures like ventral roots were observed alternating with dorsal roots on the same side of the body and aligned with the dorsal roots on the opposite side. Some authors reported that these were typical ventral roots containing nerve fibers that ran to the periphery to innervate muscle fibers in the myomeres; others thought that the muscle fibers sent a process medially to contact the spinal cord ${ }^{49}$.

The confusion was resolved by Flood using light and electron microscopy in a study of the apparent ventral roots ${ }^{49}$. He observed that the muscle fibers do indeed send processes medially to contact the spinal cord, and the processes sometimes even contained myofilaments. The 'ventral roots' observed by other workers are muscle processes, not nerves. These processes contact a specialized region of the ventral portion of the cord which lacks a glial covering and con- 
tains a large number of boutons with vesicles. This region is divided into a dorsal compartment containing large boutons with relatively small vesicles (50-60 $\mathrm{nm}$ diameter) and a ventral compartment having smaller boutons and relatively large vesicles $(100 \mathrm{~nm}$ diameter). The processes of the two different types of muscle fibers in the myomere contact these two compartments in the cord (Fig. 1). The superficial fibers send long thin processes to contact the dorsal compartment, while the deep fibers send relatively large processes to contact the ventral compartment. Thus, there is a spatial segregation of the region of contact of the two different muscle fiber types with the cord.

\subsection{Motoneurons}

The identification of somatic motoneurons in Branchiostoma must be regarded as tentative because of the difficulty of recognizing motoneurons without a characteristic axon entering a ventral root. The confusion in the literature concerning the identification of motoneurons in Branchiostoma is reviewed by Bone ${ }^{14}$. He acknowledged the difficulty in tracing processes of cells into the ventral roots, but erred in concluding that the processes from motoneurons actually exit in the roots.

Bone $^{14}$ identified cells with processes that appeared to enter ventral roots as motoneurons in his silver-stained material. According to Bone, the motoneurons form fan-shaped arrays in the cord with their medial sides in contact with the central canal and their lateral processes converging on a ventral root. He recognized 3 different types. The first type (SMi, see Fig. 2) consists of a single large cell per body hemi-segment, which has an axon arising as a collateral of a process that runs longitudinally in the cord in a ventrolateral tract. These cells are larger than any of the other motoneurons and have a prominent large vacuole above the nucleus. Most of the motoneurons Bone observed belong to a second type (SMii, Fig. 2). They are smaller than the first type, and there are about 10-15 per hemi-segment. Their axons, like those of the SMi cells, arise as collaterals of processes continuing in the longitudinal tract. The medial portion of the third type (SMx) of motoneuron terminates on the side of the central canal opposite the cell body. There is only one SMx cell per hemi-segment. These SMx cells may not be moto-
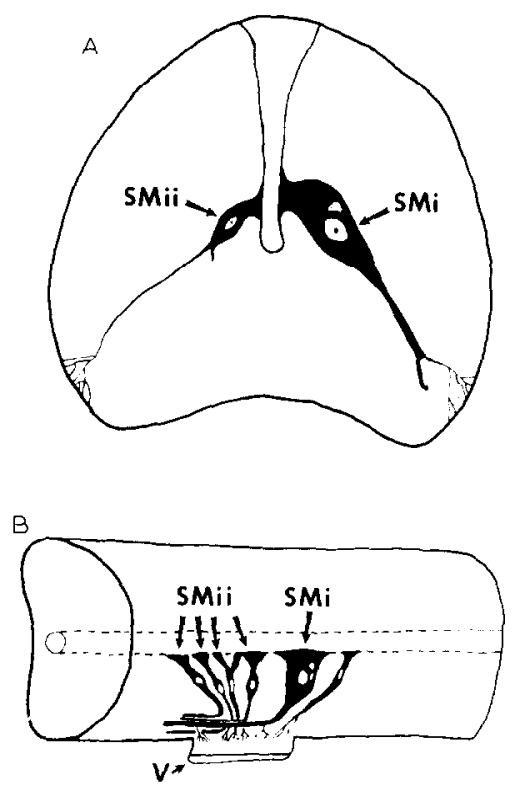

Fig. 2. Spinal motoneurons in Branchiostoma. A: transverse section of the spinal cord showing examples of the two classes of motoneurons (SMi and SMii) identified by Bone ${ }^{14}$. B: SMi and SMii motoneurons in horizontal view. Rostral is to the right. V, ventral root. Redrawn with modifications (ref. 14).

neurons because Bone could not trace their axons to a ventral root.

Bone suggests that the large SMi cells may represent the motoneurons arising earliest in development, around which the future motor system (including the SMii cells) develops. The organization in adult Branchiostoma would then be similar to, and in his opinion homologous with the organization in larval vertebrates ${ }^{34,35,149,159}$ (see Sections 3, 5 and 6).

Many studies that have used silver stains to study motoneurons in larval vertebrates $\mathrm{s}^{34.35 .150 .158 .159}$ have reported axons from motoneurons innervating axial muscle that arise as collaterals of processes that run longitudinally in the cord, and in some cases contact more caudal motoneurons. These longitudinal processes form an important element in Coghill's model of the motor organization of the spinal cord in larval urodelcs $^{34.35}$ (see Section 6.1.3.). Generally, more recent studies have failed to confirm the existence of these longitudinal processes ${ }^{13,46,88}$. Although Bone acknowledged that it was very difficult to actually see an axon arising from a process continuing in the longitudinal tract, he still concluded that most of the motor axons in Branchiostoma arose in this manner. $\mathrm{He}$ did, however, occasionally observe processes run- 
ning directly to the ventral root without any contribution to the longitudinal tract.

The first two types of cells (SMi and SMii) observed by Bone are probably motoneurons because their axons branch extensively just before they reach the region of the ventral root (Fig. 2). One might expect this sort of morphology of motoneurons that form the many boutons in contact with muscle fibers at the surface of the cord as observed in subsequent studies by Flood ${ }^{49}$. The axonal branching that occurs peripherally at the muscle in vertebrates, seems to occur within the spinal cord in Branchiostoma.

The actual relationship between the motoneurons observed by Bone and the muscle fibers observed by Flood is unknown. One might predict that the two different compartments in the cord are formed by processes from the two types of motoneurons. The large motoneurons (SMi) may form the boutons in the ventral compartment which contact deep muscle fibers, while the smaller motoneurons (SMii) might form the boutons in the dorsal compartment which contact the superficial muscle fibers. If this were the arrangement then all of the deep muscle fibers in one hemi-segment would be contacted by the same motoneuron because there is only one SMi cell per hemisegment. This could account for some observations that all of the plates in a single myomere behave as a single motor unit ${ }^{14}$. A clarification of the relationship between motoneurons and muscle fiber types in Branchiostoma requires studies, similar to those already completed on agnathans ${ }^{133}$, that combine intracellular recording from motoneurons and muscle fibers with intracellular staining.

\section{AGNATHANS}

\subsection{Lampreys}

The following description refers to adult lampreys except where indicated.

\subsubsection{Musculature}

The axial musculature of lampreys is myomeric, with each myomere formed from a stack of similar subunits (Fig. 3). Each subunit spans the mediolateral extent of the myomere, and contains muscle fibers that run from myoseptum to myoseptum. The subunits in Petromyzon marinus consist of 4 central layers

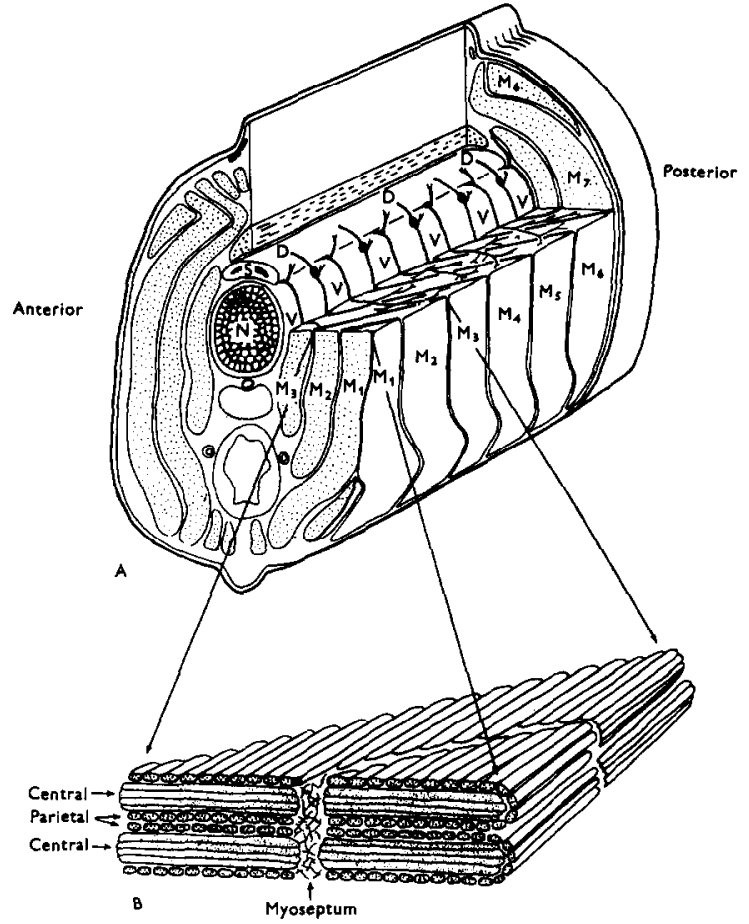

Fig. 3. Organization of the musculature and spinal nerves in lampreys. A: cut-away view of the body showing the arrangement of the myomeres (M1-M7), which are folded so that anterior ones overlap more posterior ones. The spinal cord (S) lies above the notochord (N). Dorsal (D) and ventral (V) roots arise alternately from the spinal cord; the ventral root branches into dorsal and ventral rami. B: enlargement of parts of two myomeres showing the structure of the subunits that form them. Each subunit consists of 4 layers of central fibers surrounded, except at the medial and myoseptal surfaces, by a single layer of parietal fibers. Reproduced (ref. 103) with permission of Cambridge University Press.

of 30-40 large fibers surrounded by one layer of smaller parietal fibers. The individual muscle fibers in a subunit are not each surrounded by a basement membrane as they are in all other vertebrates; instead, the subunit as a whole is surrounded by a basement membrane, which, because of the layered arrangement of the subunit, only contacts the surface of the parietal fibers and the medial side of the most medial central fibers ${ }^{132}$.

The central fibers are relatively large, they generatc spikes following stimulation of peripheral nerves, and they have the ultrastructure and histochemistry typical of fast, white muscle fibers ${ }^{132}$. The smaller parietal fibers are non-spiking, and have the ultrastructural and histochemical characteristics of slow, red muscle. After stimulating a peripheral 
nerve the tension generated in the axial musculature shows a fast and a slow phase of relaxation. These phases presumably correspond to the contributions to tension from the central and parietal muscle fibers respectively ${ }^{132}$.

The organization of the muscle fibers in the myomeres of agnathans apparently changes during development. In early larvae the arrangement is similar to Branchiostoma, with flat muscle cells stacked in the myomere and little or no differentiation of the muscle subunits that are present in the adult $t^{91,92,114,132}$.

\subsubsection{Innervation}

Unlike most other vertebrates, the dorsal and ventral roots of lampreys do not join after they exit the cord (Fig. 3). Electron microscopic counts show that the ventral root contains an average of 100 unmyelinated axons in adult Petromyzon marinus and 71 in adult Ichthyomyzon unicuspic ${ }^{116}$ (there is no myelin in the central or peripheral nervous system of agnathans). These numbers probably reflect the number of motoneurons per hemi-segment because motoneurons stained intracellularly have only a single axon in a ventral root ${ }^{115,116}$. After exiting the cord the ventral root branches into dorsal and ventral rami which provide the innervation of the myomeres ${ }^{103}$. Each of the parietal muscle fibers is multiply innervated by axons that run in the connective tissue between the muscle subunits. Only the most medial of the central fibers are innervated, at their medial edge. The more lateral central fibers are not directly innervated, but are electrically coupled to the medial fibers $^{132}$.

\subsubsection{Motoneurons}

The motoneurons in lampreys are approximately $25-50 \mu \mathrm{m}$ in diameter, and are located in the lateral gray matter of the spinal cord (Fig. 4$)^{133}$. Using simultaneous intracellular recordings from motoneurons and muscle fibers, Teravainen and Rovainen ${ }^{133}$ showed that an individual motoneuron innervates only parietal or only central muscle fibers, but not both. The motoneurons innervating parietal muscle fibers are slightly smaller than those innervating central fibers, but are otherwise similar in general morphology, with transversely oriented dendrites ramifying extensively among fiber tracts in the lateral portion of the cord ${ }^{58,133}$. Motoneurons typically in- nervate 5-12 myomeric subunits confined to an individual myomere, although occasionally they innervate fibers in 2 or 3 myomeres ${ }^{133}$. The motoneurons innervating the parietal fibers are more readily activated during spinal reflexes than those innervating the central fibers ${ }^{134}$. The parietal motoneurons are those usually active during fictive swimming in in vitro preparations $\mathrm{s}^{26,115}$.

Different motoneurons, illustrated in Fig. 4, innervate the dorsal and ventral extremes of the myomeres ${ }^{143}$. Dendritic arbors from cells innervating ventral myomere are dense, fan-like, and have branches near the midline of the cord. Arbors of dorsal myomere motoneurons are larger, and less dense, with few branches near the midline. The differences in their dendritic arbors are correlated with differences in synaptic input during fictive locomotion. Although their dendritic arbors differ, the somata of motoneurons innervating dorsal and ventral myomere are intermingled in the motor column ${ }^{143}$.

The motoneurons in the ammocete (larval lamprey) have not been studied with modern neuroanatomical techniques. The older literature is reviewed by Whiting ${ }^{149}$. He recognized two types of motoneurons in preparations stained with methylene blue or silver. These two types were compared to the two types identified by Coghill ${ }^{34,35}$ and Youngstrom ${ }^{159}$ in urodeles. The first class is, according to Whiting, similar to primary motoneurons in Ambystoma (see Section 6.1.3.). Cells in this class have dendrites in association with the descending giant fiber system in the cord and an axon that arises as a collateral of a process that continues caudally in the cord in the socalled 'ventral motor tract'. The second class is somewhat similar to secondary motoneurons in Ambysto$m a$. Their relatively small axons are not associated with the descending giant fiber system. By analogy with the motor system in urodeles, the two groups of motoneurons were thought to be involved in 'total' body movements (those caused by primary motoneurons in urodeles) and 'local' movements (those caused by secondary motoneurons in urodeles) respectively.

The influence of the work by Coghill and Youngstrom is apparent in Whiting's work with the ammocete as it was in Bone's studies of Branchiostoma. More recent studies in other anamniotic vertebrates indicate that the axons of the primary motoneurons 

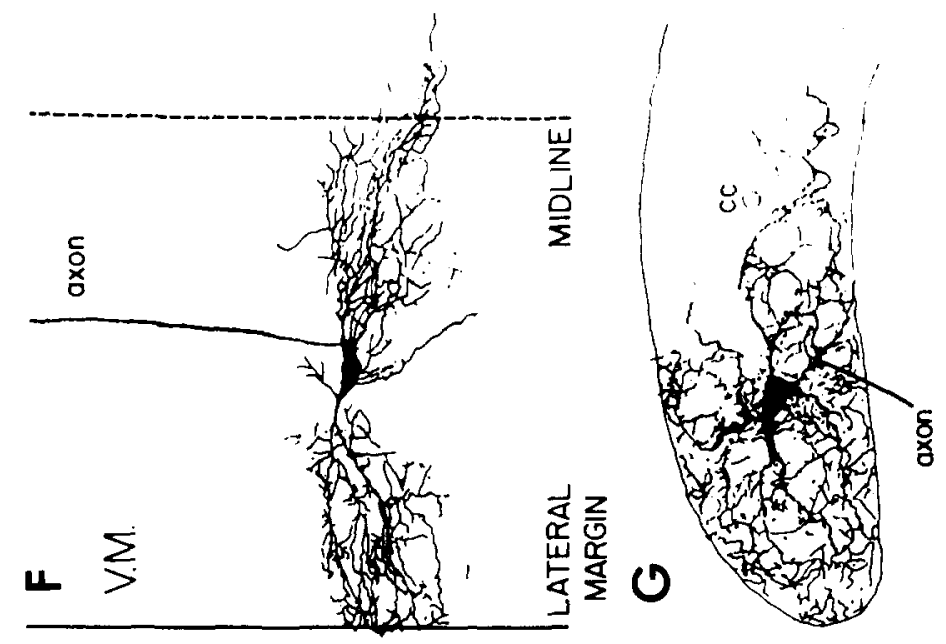

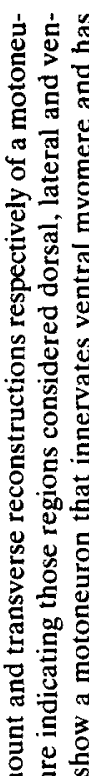
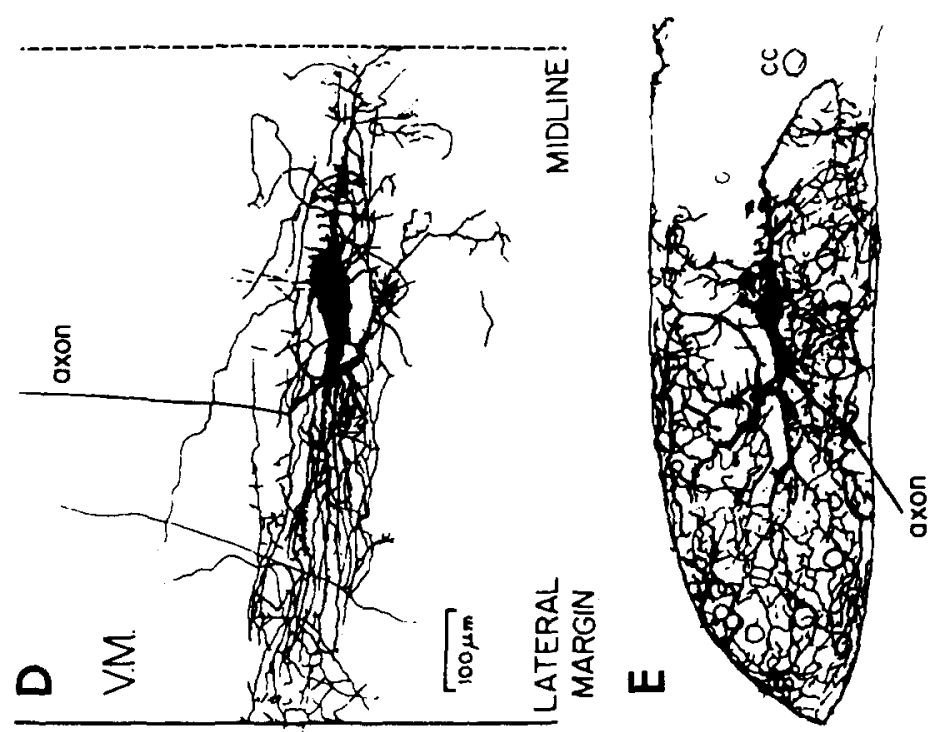

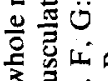

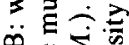

$\infty \sum \sum$

《吉已?

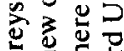

言需范

프

象㝴

ह

要管吕

导要这

ㅇ

罂言

훙
$\overline{0}$
क्रे
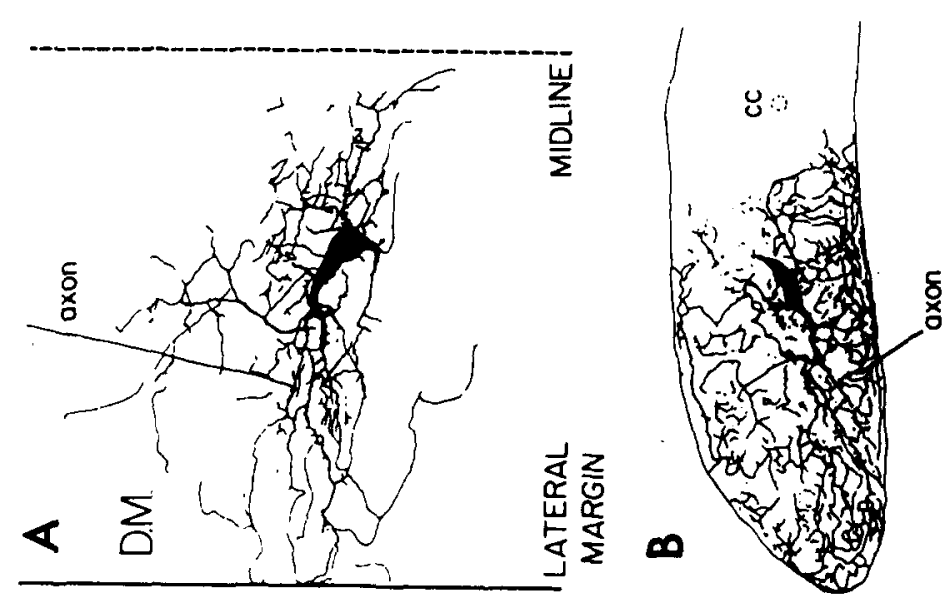

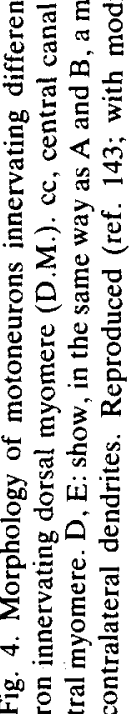


do not arise as collaterals of descending processes. They probably do not in ammocetes either, but the issue will not be resolved until the motor system of ammocetes is studied with modern tracing techniques.

\subsection{Hagfish}

\subsubsection{Musculature}

The axial musculature of hagfish is myomeric as in most anamniotic vertebrates. Each myomere consists of subunits that are similar in general respects to those present in lampreys. They differ from those in lampreys in that each subunit in hagfish has a layer of slow parietal fibers ${ }^{16,51}$ on only the ventral and lateral, but not the dorsal side. The fast, central muscle fibers are not sheet-like as they are in lampreys; instead, they are cylindrical and form approximately 3 layers in the central portion of the subunits. All of the muscle fibers in a subunit are surrounded individually by separate basement membranes ${ }^{114}$. Bone ${ }^{16}$ indicates there are about 1500 muscle fibers in a myomere of Myxine glutinosa, with 150 of them belonging to the slow type. A count of the number of slow muscle fibers in the myomeres of Myxine glutinosa from a photo in Flood and Storm-Mathisen ${ }^{51}$ indicates there are substantially more than 150 slow muscle fibers per myomere. Bone ${ }^{16}$ used small hagfish (5-7 inches), and the discrepancy might be explained if the number of muscle fibers is related to the size of the animal ${ }^{40}$. There is also some histochemical evidence for a third muscle fiber type in myomeres of hagfish $^{51}$.

\subsubsection{Innervation}

Hagfish have typical dorsal and ventral roots; the muscle fibers are innervated by motor axons traveling in the ventral root and its branches. In the region of the gill, branches of the dorsal and ventral roots join to form a mixed ventral ramus, but in the tail the dorsal and ventral roots remain separate and each gives rise to separate peripheral branches ${ }^{102}$. Goodrich has argued that the fusion of dorsal and ventral roots in hagfish evolved independently of the fusion present in gnathostome vertebrates ${ }^{56}$. He suggests that the absence of a fusion of dorsal and ventral roots in Branchiostoma and lampreys indicates that this separation is the primitive condition for vertebrates. He further points out that the relationship be- tween the fused dorsal and ventral roots and the intersegmental arteries in hagfish differs from the relationship between these structures in gnathostomes, and these differences also support the notion of a separate origin of the fusion of the roots in hagfish.

The ventral roots in the mid-trunk region contain 140-160 unmyelinated axons based on light microscopic counts. These are probably underestimates and should be confirmed electron microscopically. The majority of axons range in size from one to two micrometers; however, there is a single large (3-4 $\mu \mathrm{m})$ axon in each root ${ }^{16}$. The ventral root forms two major branches: a dorsal ramus that runs along the medial face of the dorsal portion of the myomere, and a ventral ramus that runs along the medial side of the ventral portion of the myomere ${ }^{102}$. One spinal nerve usually innervates two adjacent myomeres $^{15,102}$.

Each slow muscle fiber is innervated by two motor axons, has terminals spread over the surface of the muscle fiber ${ }^{4.15}$, and produces only junctional potentials, no action potentials ${ }^{4}$. The fast fibers are innervated focally at their myoseptal ends. Each fast fiber is separately innervated; they are not electrically coupled as they are in adult lampreys ${ }^{114}$. The fibers have typical overshooting action potentials, and are each innervated by a single axon ${ }^{4.16}$.

\subsubsection{Motoneurons}

The motoneurons occupy the ventral and lateral portions of the nearly horizontal gray matter in $M y x$ ine. Bone ${ }^{15}$ recognizes 3 cell types in the spinal cord with processes in the ventral roots. Two of these he believes are somatic motoneurons and the third is possibly a viscero-motor cell. Presumptive motoneurons in the first class are the largest (most are greater than $25 \mu \mathrm{m}$ in diameter) and the most common. They are located in the lateral portion of the gray matter, lateral to the region containing the motor axons running to the ventral root. A dendrite from them extends medially along the ventral edge of the gray matter and gives rise to the axon. The most medial portion of this process may ramify in the region of the medial longitudinal fasciculus (MLF) and sometimes crosses to the opposite side of the cord in the ventral commissure. These large cells also have lateral dendrites that ramify in the lateral and dorsolateral portions of the white matter. 
The second class of motoneuron is smaller and less abundant. This type is located in the ventromedial portion of the gray matter, closer to the central canal than the larger type. These small cells have dendrites in the ventral white matter, and their axon runs laterally toward the ventral root.

Bone was unable to identify the cell of origin of the single largest axon in the ventral root. This axon was observed running longitudinally in the MLF where it turned to exit in the ventral root.

The relationship between the motoneurons and the muscle fiber types in hagfish is unknown. Bone ${ }^{15}$ draws some parallels between the motoneurons in hagfish and those observed by others in ammocetes $^{149}$ and in Ambystoma ${ }^{159}$. In his opinion the first and largest type of motoneuron in hagfish might be equivalent to the primary motoneurons in the larvae of lampreys and urodeles. These cells have in common a large size and an association with the large descending fiber tracts of the MLF. He suggests that this first type of motoneuron may innervate the fast, central muscle fibers.

The second type of motoneuron recognized by Bone is, in his view, not entirely comparable to the secondary motoneurons present in the larvae of lampreys and urodeles. Although they are smaller than the first type, as secondary motoneurons are smaller than primary ones in other vertebrates, the small and large motoneurons in hagfish occupy different relative positions from the relative positions of primary and secondary motoneurons in other vertebrates.

There are some problems with Bone's interpretation of the motoneurons in hagfish. In other anamniotes examined ${ }^{34,35,46,67,88,97,98,158,159}$ there are generally many fewer primary motoneurons than secondary ones. If primary motoneurons formed the most abundant class recognized by Bone then the relative abundance of the different types of motoneurons in hagfish would differ from other anamniotes. Primary motoneurons also typically have an axon that runs for some distance longitudinally in the region of the MLF before exiting in the ventral root. Neither of the two types of motoneurons identified by Bone have an axon with such a longitudinal course.

The details of the arrangement of motoneurons and the relationship between motoneurons and muscle fiber types in hagfish also need to be clarified using modern anatomical and physiological techniques.

\section{CARTILAGINOUS FISHES}

\subsection{Musculature}

Most Elasmobranchs that rely on axial muscles for locomotion have a myomeric arrangement of musculature. The axial musculature of rays ${ }^{39}$ and probably skates, is reduced in conjunction with the primary role of the fins in locomotion.

The myomeres in Elasmobranchs, as in most fishes, are complexly folded. They form a $\mathrm{W}$ shape in a lateral view, with the top of the $\mathrm{W}$ facing rostrally. Those muscle fibers in the superficial portion of the myomeres are oriented parallel to the long axis of the body, while the deeper fibers are oriented at an angle between $10^{\circ}$ and $30^{\circ}$ relative to the body axis ${ }^{2}$.

The muscle fibers are divided into as many as 5 types based on histochemical criteria ${ }^{17,20,69,70}$. The significance of some of the types is unclear because they form only a very small portion of the fibers in the myomeres. The bulk of the myomeres is formed by the two most abundant fiber types that are also clearly functionally different. A red muscle fiber type occupies the superficial portion of the myomeres, forming a band along the lateral surface just beneath the skin, as in bony fish (Fig. 5). In the tail, the band is thickest near the lateral line, and thins dorsally and ventrally. Red fibers are relatively small and specialized for aerobic metabolism. They contain a large amount of fat and myoglobin, many mitochondria, and a high concentration of oxidative enzymes, and are well vascularized ${ }^{18,20,69,70}$. Red muscle forms about $18 \%$ of the myomeres from the tail of Scyliorhinus $^{18}$. A white fiber type occupies the deeper portion of the myomeres, and forms roughly $80 \%$ of the myomeres in the tail. The white fibers are larger in cross-section than the red ones. They have relatively little fat or myoglobin, fewer mitochondria, and are not well vascularized.

As in other fish (see Section 5.1.) both red and white fibers increase in size and number as the sharks grow, although the maximum number of white fibers in some sharks is reached before hatching and may decline thereafter ${ }^{86}$.

Bone ${ }^{18}$ used extracellular recordings from the red and white regions of the myomeres of spinal Scylio- 


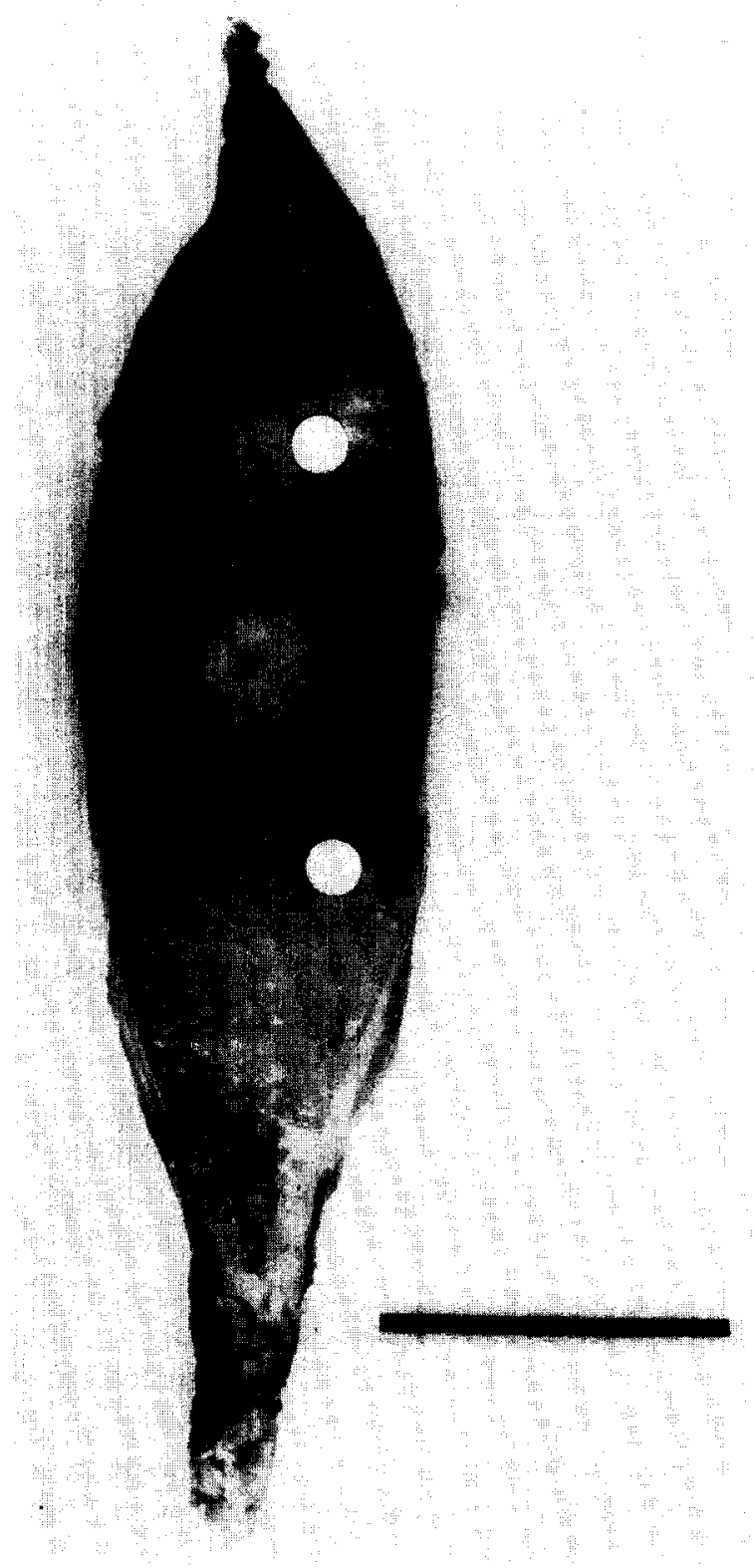

Fig. 5. A cross-section through the tail of a goldfish, showing the division of the musculature into a superficial red (solid arrows) and deeper white (the white dots are within the white muscle) portion. The muscle is also divided into dorsal (epaxi$\mathrm{al}, \mathrm{E})$ and ventral (hypaxial, H) portions by a horizontal septum (open arrows). An asterisk marks the location of the spinal cord. Reproduction (ref. 46)

rhinus to show that the red muscle was active during sustained swimming, while the white was active only during 'vigorous' movements. During sustained swimming, Bone could record extracellular activity with an amplitude of $150 \mu \mathrm{V}$ in the red muscle. Elec- trical activity was recorded in the deep white muscle only after causing the shark to swim vigorously by pinching the tail. The amplitude of this electrical activity was very large $(1-2 \mathrm{mV})$ relative to that recorded in red muscle. This involvement of the red muscle in sustained locomotion is consistent with its anatomical and histochemical specializations for aerobic metabolism.

Junctional potentials, but no action potentials, are recorded intracellularly from the red fibers. Bone thought that the $150 \mu \mathrm{V}$ activity recorded extracellularly in the red muscle of spinal dogfish was not junctional potentials recorded extracellularly, but instead represented action potentials recorded from the nerves in the red muscle. However, Roberts ${ }^{10}$ noted that curare abolished the extracellular recordings from red muscle, indicating they were extracellular recordings of junctional potentials and not action potentials in nerves. The white fibers can generate action potentials, and these action potentials probably account for the 1-2 $\mathrm{mV}$ potentials recorded from white muscle during vigorous movements ${ }^{20.71)}$.

\subsection{Innervation}

The ventral roots in Scyliorhinus exit the spinal cord rostral to the dorsal roots of the same segment. According to Roberts ${ }^{111}$ there are 3 main branches of each ventral root. A dorsal branch arises before the dorsal and ventral roots have joined and runs deep in the epaxial musculature. A medial ramus arises after the dorsal and ventral root have joined and runs laterally, dorsal to the horizontal septum and under the lateral line, where it branches in the superficial muscle. After giving rise to the medial ramus the remaining branch of the dorsal and ventral roots forms a ventral ramus which runs ventrally deep in the hypaxial muscle ${ }^{111}$. Mos and Williamson present a more complex branching pattern of the spinal nerves in the same species. The ventral root branches into two major rami, a dorsal and a ventral one. Each of these rami has many branches with the majority entering white muscle; however, both rami also have horizontal branches that enter red muscle.

The contributions of the dorsal and ventral roots to the ventral ramus remain separate in the proximal portions of the ventral ramus of Scyliorhinus and some other Elasmobranchs, but in still other Elasmobranchs (e.g. Raja), they intermingle in the ramus ${ }^{111}$. 
In Scyliorhinus one spinal nerve innervates muscle fibers in two adjacent myomeres ${ }^{111}$.

The red fibers are innervated at nerve terminals spread over the surface of the muscle fibers from myoseptum to myoseptum. These terminals usually arise from more than two axons and are spaced 150-200 $\mu \mathrm{m}$ apart in Scyliorhinus ${ }^{12}$.

The white fibers are innervated by axons terminating on only one end of the fiber ${ }^{18}$, where two different nerve branches are visible. The presence of different types of vesicles in the terminals of these two processes has caused speculation that one of the fibers might be autonomic ${ }^{19,100}$. However, the processes do not always contain different types of vesicles, and they might even be branches of the same cell ${ }^{70}$. One of the terminals may represent some sort of neuromodulatory system, but the evidence is meager.

The ventral root in Scyliorhinus contains about 300 axons in $12 \mathrm{~cm}$ fish. The number increases to approximately 420 in $40 \mathrm{~cm}$ fish and stays constant thereaf$\operatorname{ter}^{86}$. These numbers probably reflect the number of motoneurons per hemi-segment ${ }^{111,112}$. Roughly $30 \%$ of the axons in the ventral root travel in branches of the spinal nerve that enter red muscle. The largest axons in the ventral root (which presumably arise from the larger motoneurons that innervate white muscle, see below) are grouped together as in most anamniotic vertebrates (ref. 86; and below).

\subsection{Motoneurons}

The cell bodies of the motoneurons are located in the ventral portion of the ventral horn. They have dendritic processes that are oriented in the transverse plane and extend throughout much of the ipsilateral white matter. Some dendrites also cross ventrally to the contralateral ventral horn. The motoneurons form a continuous distribution with respect to axonal diameters, conduction velocities, and the areas of the cell bodies ${ }^{112}$. Horseradish peroxidase labeling of the axial musculature in Scyliorhinus, indicates that there is a rough segregation of motoneurons innervating red and white muscle; the red muscle is innervated by small motoneurons in the lateral portion of the motor column, while the white muscle is innervated by larger motoneurons in its medial part $^{86}$.

Droge and Leonard ${ }^{39}$ examined the motoneurons innervating the reduced epaxial muscle of the sting- ray, Dasyatis sabina. These motoneurons are located in a rather unusual position in the ventral portion of the gray matter, ventral, and slightly lateral to the motoneurons innervating the large pectoral fins. There is evidence that the number of motoneurons per body segment in Dasyatis increases in older animals $^{79}$.

\section{BONY FISHES}

\subsection{Musculature}

The myomeres of bony fish are generally similar to the myomeres of Elasmobranchs. They are complexly folded, with the muscle fibers in the superficial portion of the myomeres running parallel to the long axis of the body, and the deeper fibers running at different, often large $\left(35^{\circ}\right)$ angles relative to the body axis.

Numerous studies have dealt with the muscle fiber types in the myomeres of bony fish (reviewed in refs. $20,69,70)$. Although as many as 5 different fiber types have been recognized, the bulk of the muscle in the myomeres is composed of two different fiber types as in cartilaginous fish. A band of red fibers typically lies superficially along the side of the body, parallel to the vertebral column as in the section from the tail of a goldfish shown in Fig. 5. A much larger mass of white fibers lies deep to the red. There are some exceptions to this typical pattern of segregation of the fibers into a superficial red and deep white portion. For example, in Salmo gairdneri a mosaic pattern is formed by red fibers scattered through the deep white muscle ${ }^{72}$, and in tuna the red muscle mass extends deep into the mid-portion of the myomeres $^{69,106}$.

The red fibers have anatomical, biochemical and histochemical features usually associated with aerobic metabolism, including a relatively large number of mitochondria, a high concentration of myoglobin and aerobic enzymes and a dense system of capillaries $^{20,69,70}$. In contrast the white fibers have lower numbers of mitochondria, lower concentrations of myoglobin and aerobic enzymes and are less well vascularized. Thus, they are specialized for anaerobic metabolism. The numbers and sizes of the red and white fibers in the myomeres increase with growth in conjunction with an increase in the size but not the number of the motoneurons that innervate 
them ${ }^{127.141 .154}$.

The red and white fibers of bony fish are functionally different. However, the functional difference is not always as distinct as it is in Elasmobranchs. There are two different patterns of innervation of the red and white muscle of bony fish that correlate with two different patterns of activity in the red and white muscle during locomotion. The red and white fibers of Sarcopterygians (Dipnoans and Latimeria), primitive Actinopterygians (Halecostomi, Ginglymodi, chondrosteans, and basal teleosts - Elopomorphs and Clupeomorphs) are innervated like the red and white fibers in cartilaginous fish ${ }^{21}$. The red fibers receive a distributed innervation with nerve terminals spread over the surface of the muscle fibers, while the white are innervated only at the myoseptal ends of the fibers. Electromyographic studies of swimming in fish with this pattern of innervation reveal a very clear functional difference between the red and white muscle, as previously described for Elasmobranchs (see Section 4.1.; refs. 18, 22). Only junctional potentials are recorded intracellularly from the red muscle fibers after stimulation of spinal nerves. In contrast, the white fibers generate typical action potentials that are propagated over their surface $8,18,60$.

The muscle fibers of most advanced teleosts show a different pattern of innervation from those of other bony fish. In advanced teleosts both the superficial red and deep white fibers receive a distributed innervation with terminals spread over the surface of the fibers $^{21}$. In these fish the functional difference between the red and white muscle is not as clear as in other bony fish; the red muscle still plays a primary role at slow sustained speeds and the white a primary role during burst swimming, but the white muscle is also active at high sustained swimming speeds ${ }^{22,66,71}$. There are some discrepancies in different studies of the same species with respect to the lowest speed at which the white muscle is first active (Cyprinus car$\left.p_{i o} o^{22,71}\right)$. These differences may result from differences in the locations of the recording sites in the white muscle. Nevertheless, the white muscle fibers of advanced teleosts clearly become active at relatively lower speeds than the terminally innervated white muscle fibers in Elasmobranchs and primitive bony fish.

The electromyographic activity recorded in the white muscle when it is first recruited in the mirror carp (Cyprinus carpio) has a relatively low amplitude (200 $\mu \mathrm{V}$ peak to peak) and is very similar to the electrical activity recorded in red muscle. At higher swimming speeds spike-like activity ( $500 \mu \mathrm{V}$ peak to peak) is evident ${ }^{22}$. These differences in the electrical activity recorded in white muscle at different swimming speeds underly speculation that either there are at least two fiber types in the white muscle, one nonspiking type active during sustained swimming, and the other, spiking-type active during burst swimming, or that tension in individual white muscle fibers results from junctional potentials at sustained speeds, and these same fibers generate tension at burst speeds by producing action potentials ${ }^{22}$

There is some evidence that supports the latter explanation. The deep white fibers in the carp are fairly homogeneous histochemically, which argues against the presence of two fiber types. Individual white fibers produce both junctional potentials and action potentials after stimulation of spinal nerves ${ }^{8.66}$, consistent with the possibility that they may do so during normal swimming. Observations of white fibers from the pectoral fin of the snake fish (Ophiocephalus argus) during stimulation of the motor nerve innervating the fin also suggest that the white fibers are contracting when only junctional potentials are recorded in them ${ }^{131}$. Finally, in zebrafish subthreshold depolarizations of individual white fibers in the myomeres produce graded contractions of the fibers, and the same fibers produce action potentials and rapid twitches upon suprathreshold depolarization ${ }^{148}$. These individual fibers are innervated by as many as 4 motoneurons. One of the motoneurons innervating each fiber belongs to a class of large, primary motoneurons which are important for rapid movements in fish; the other motoneurons are smaller, secondary ones implicated in the production of slower, weaker movements among anamniotes (see Section 5.3.). If only the secondary motoneurons were active at low swimming speeds, and their activation was not sufficient to bring the muscle fibers to threshold, then the subthreshold depolarization should produce graded contractions of the fibers and might account for the low amplitude electrical activity in the white muscle of teleosts at these low swimming speeds. At higher speeds and during large accelerations the larger, primary motoneurons innervating each fiber might be active, bringing the fiber to threshold, and producing 
a rapid twitch and larger amplitude electromyographic activity. For this hypothesis to be correct, the activation of secondary motoneurons must not bring the muscle fibers to threshold. The notion that individual fibers might sometimes produce graded contractions in response to subthreshold depolarizations, and at other times produce action potentials and rapid twitches is an unconventional one for vertebrate muscle fibers, and consequently deserves closer examination.

An alternative, more conventional explanation is that both secondary and primary motoneurons bring the muscle fibers to threshold, and the differences in the electromyographic activity in white muscle at low and high speeds are related to the smaller number of muscle fibers innervated by each secondary motoneuron relative to each primary one ${ }^{148}$. If only secondary motoneurons are active at low speeds, the low amplitude electromyographic activity may be a consequence of the small number of muscle fibers activated synchronously by each secondary motoneuron. At higher speeds, if the primary motoneurons are active, a larger number of muscle fibers would fire synchronously, and larger electromyographic spikes would be produced. This explanation does not readily account for the similar amplitudes of electromyographic activity recorded at low speeds in white muscle and electromyographic activity recorded in the tonic red muscle. If this possibility is correct then the electromyographic activity due to action potentials in white fibers at low speeds must for some reason be similar to electromyographic activity resulting from subthreshold depolarizations of red muscle fibers.

In the myomeres of Cyprinus carpio there is some evidence for a functionally different, third fiber type that is located between the red and white fibers, and that becomes active at speeds between those at which red and white fibers are active ${ }^{71}$.

\subsection{Innervation}

The dorsal and ventral roots of teleosts exit separately from the vertebral column. The mixing of axons from the dorsal and ventral roots in the peripheral nerves of fishes is usually not nearly as complete as in amniotic vertebrates. Often branches of the dorsal and ventral root do not even join, and where they do they tend to occupy separate bundles in the mixed nerve ${ }^{111}$.
Axons in the ventral root travel in 3 major branches of the spinal nerves (Fig. 6). The dorsal ramus arises from the ventral root before the ventral root has received any contribution from the dorsal root, and runs caudally and dorsally in the trunk musculature where it joins a 'sensory' dorsal branch from the next posterior body segment ${ }^{8,46,55,62,95,138}$. The medial ramus in some cases contains contributions from both the dorsal and ventral root, and in others arises from the ventral root before the dorsal and ventral roots have joined. It runs laterally in the horizontal septum to the superficial portion of the trunk musculature ${ }^{55,62,138}$ (lateral ramus of Barets ${ }^{8}$ ). The

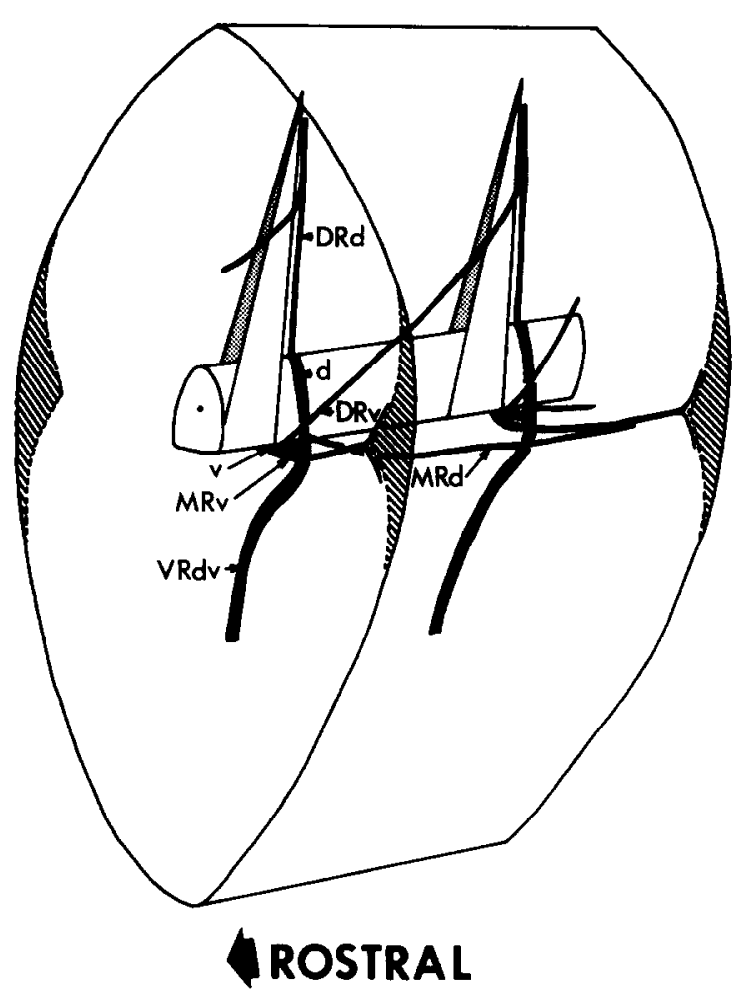

Fig. 6. Diagrammatic view of the branching pattern of spinal nerves from the tail of a goldfish. The spinal cord and the neural spines of the vertebrae of two scgments are shown within a cross-section of the tail musculature. The red muscle on either side of the body is shaded with black lines. The spinal nerves are shown in solid black. The ventral root (v) exits from the cord and forms 3 branches: a dorsal ramus (DRv) runs dorsally and caudally in the epaxial musculature; a medial ramus (MRv) runs laterally to the red muscle, and a ventral ramus joins with a branch of the dorsal root (d) and runs ventrally in the hypaxial musculature (VRdv). DRd and MRd are the dorsal and medial branches of the dorsal root respectively. Reproduction (ref. 46). 
third major branch of the ventral root, the ventral ramus, joins with a branch of the dorsal root and runs ventrally deep in the hypaxial muscle. The dorsal and ventral root contributions to the ventral ramus occupy two distinct bundles in the ventral ramus of many fish including some primitive bony fish (Latimeria, Acipenser) and a number of teleosts ${ }^{111}$.

The fields of innervation of the spinal nerve branches of fishes are important for identifying homologies between them and the branches of spinal nerves in other vertebrates. Unfortunately, the accounts in the literature are not in agreement. The field of innervation in the myomeres is difficult to determine from gross anatomical study, and the differences in the literature probably reflect this.

Some studies indicate that the medial ramus innervates only epaxial muscle ${ }^{55,62.138}$, while the dorsal ramus innervates the dorsal fin and sometimes part of the epaxial musculature. In other accounts, the medial ramus is said to innervate the superficial muscle (mainly the red muscle) in both the epaxial and hypaxial portions of the myomeres, while the dorsal ramus supplies the deep epaxial muscle and the dorsal fin musculature ${ }^{8,46,141}$. All authors agree that the ventral ramus innervates at least a part of the hypaxial musculature as well as the musculature in the fins on the ventral part of the body.

The number of axons in the ventral roots of different species of teleosts is variable. Reported numbers range from 60 to 70 in a ventral root from the trunk of zebrafish (Brachydanio rerio ${ }^{141}$ ) to 306 in a ventral root from the trunk of the marine sculpin (Cottus scorpius $\left.^{65}\right)$. The size distributions of axons from ventral roots on the trunk of the marine sculpin ${ }^{65}$, tench and catfish ${ }^{8}$ are bimodal. Barets ${ }^{8}$ presented size histograms showing that the smaller class of axons in the bimodal distributions is absent from ventral roots caudal to the anus and concluded that the smaller axons are probably preganglionic sympathetic fibers. Hudson ${ }^{65}$ indicated that the smaller class of axons innervated red muscle, but he offered no explanation of the absence of small axons in postanal ventral roots where the proportion of red relative to white muscle is greatest. The evidence presented by Barets strongly supports the conclusion that preganglionic sympathetic axons form the small class of axons in the bimodal distributions.

The size distributions of axons in postanal ventral roots are unimodal and sometimes are skewed toward the larger size classes ${ }^{8,46,141}$. In tench ${ }^{8}$, zebrafish $^{141}$ and goldfish ${ }^{46}$ the root contains a few (2-4 in adult zebrafish; $8-12$ in goldfish) relatively large axons, and in tench and goldfish these large axons are grouped together. Where these axons have been traced into the peripheral nerves, they run in the dorsal and ventral rami deep in the axial muscle, but not in the medial ramus to the superficial muscle ${ }^{46.141}$.

Individual muscle fibers in both the red and white muscle are polyneuronally innervated $3,8,17,65,131$. 145.148. The extent of polyneuronal innervation in Cottus is substantial. The white muscle fibers are innervated by 2-5 axons from nerves of each of 4 segments ${ }^{65}$. In contrast, in zebrafish very few of the white fibers are innervated by axons traveling in more than one spinal nerve ${ }^{145.148}$. Most of the white fibers are innervated by two different axons, although the number of axons innervating individual fibers ranges from one to 4 . One of the axons innervating each fiber always arises from a primary motoneuron - the others arise from secondary motoneurons (see Section 5.3.; ref. 148).

\subsection{Motoneurons}

A number of early studies tentatively identified the motoneurons in the spinal cord of bony fish ${ }^{10,61}$, $74,78,81,139$. These motoneurons have been studied more recently using horseradish peroxidase (HRP) and fluorescent labeling techniques ${ }^{36,42,46,88,141}$. Studies that apply these modern techniques are emphasized here because they allow the unambiguous identification of motoneurons.

The motoneurons in teleosts are located in the ventral portion of the gray matter in the spinal cord. Barets $^{8}$ identifies two groups of motoneurons - one located dorsally near the central canal, and the other located more ventrolaterally. Other authors indicate that the motoneurons form a continuous column extending from a region dorsally just above the central canal, ventrally, and laterally around the lateral side of the MLF $\mathrm{ML}^{46,141}$.

The largest motoneurons in the motor column are located in the extreme dorsal portion of the column, slightly dorsal to the central canal (Fig. 7). There are relatively few large motoneurons per hemi-segment, 2-4 in zebrafish with a total of about 70 motoneurons per hemi-segment ${ }^{88,141}, 8-12$ in goldfish with about 
130 motoneurons per hemi-segment ${ }^{46}$. A dendrite from the large motoneurons that gives rise to the axon, runs longitudinally and ventrally in the cord around the medial side of the Mauthner axon. Along its course this process is contacted by a small collateral from the Mauthner $\operatorname{axon}^{8,10,29,89}$ that appears to
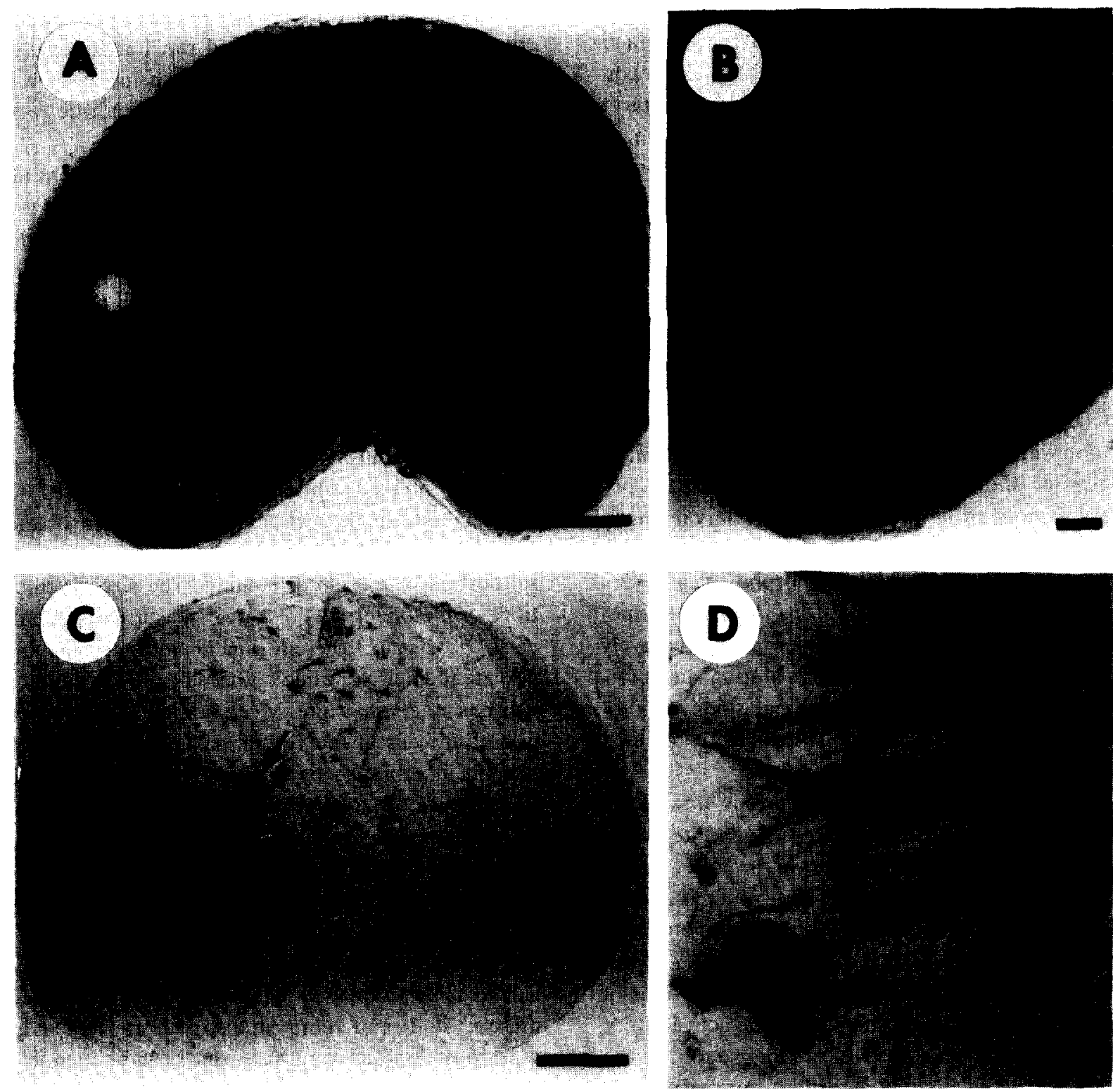

Fig. 7. The gross morphology of the spinal cord of goldfish and the general location of the cell bodies, dendrites and axons of motoneurons that innervate axial musculature. A: a $1 \mu \mathrm{m}$ semithin transverse section of the cord from the tail stained with Toluidine blue. The arrows indicate, from top to bottom: the central canal, the Mauthner axon on one side, and the motor axons located ventrally just before they exit in the ventral root. White dashes roughly outline the region occupied by motoneurons. A white dot shows a lightly stained region occupied by the dendrites of motoneurons. Bar $=100 \mu \mathrm{m}$. B: a more highly magnified view of the bottom left portion of A showing the Mauthner axon (top arrow) and the motor axons (bottom arrows). The largest axons are located on the medial side of the group of motor axons. Bar $=20 \mu \mathrm{m}$. C: a transverse section (not counterstained) of the spinal cord showing, on the left side, HRPfilled motoneurons spread throughout most of the transverse extent of the medial motor column. A star shows the position of the central canal and an asterisk shows the location of the Mauthner axon on the left side. An arrow points to a large, primary motoneuron in the dorsal portion of the column. Arrowheads point to smaller, secondary motoneurons, ventral to the large one. Bar $=100 \mu \mathrm{m} . \mathrm{D}: \mathrm{a}$ more highly magnified view of the HRP-filled motoneurons in C. An asterisk marks the Mauthner axon. Bar $=20 \mu \mathrm{m}$. Reproduction (ref. 46). 
form a chemical synapse with the motoneuron ${ }^{29}$. Intracellular recordings from motoneurons during a startle response initiated by the Mauthner cell indicate that the large motoneurons receive a short latency, possibly monosynaptic connection from the Mauthner cell and are the first motoneurons activated during the startle response $\mathrm{e}^{37,38,155}$. These conclusions have recently been confirmed using intracellular recordings followed by dye injections to unambiguously identify the motoneurons ${ }^{48}$. The axons of these large motoneurons are the large axons in the ventral root, which travel in peripheral nerves to the deep portions of the axial musculature ${ }^{46,141}$. A population of relatively large motoneurons, very similar to the large motoneurons observed in adults, are the first motoneurons born in embryonic zebrafish ${ }^{42,88,90}$. All of these features including a relatively large size, a relatively small number of cells, a process in association with descending processes in the MLF, and an early time of differentiation, are characteristic of primary motoneurons present in many larval anamniotes. The relationship between primary motoneurons in larval fish ${ }^{42,88}$ and the morphologically very similar class of large motoneurons in adults has not been established. However, in view of the relatively minor reorganization that occurs during metamorphosis in many teleost fish, the populations of motoneurons present in the larvae are most likely retained in the adult.

The axons of primary motoneurons in teleosts (goldfish and zebrafish) arise from a dendrite that is associated with descending fibers in the MLF, in particular the Mauthner axon. This association is characteristic of primary motoneurons in anamniotes (see Sections $3.2 .3 ., 6.13 .3 .6 .3 .3$.). In fish it is clearly important in the generation of abrupt accelerations of the body through direct, monosynaptic activation of the largest motoneurons by descending axons in the MLF. The association of dendrites of primary motoneurons with the MLF in other anamniotes probably plays a similar functional role.

The bulk of the motoneurons in the motor column of teleosts is smaller than the primary ones, and most of these small cells are located ventral to the largest

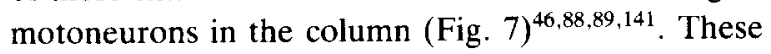
cells differentiate later than primary motoneurons, and consequently have been called secondary motoneurons ${ }^{88}$. The axons of some of these smaller cells pass lateral to the Mauthner axon along their path to the ventral root.

The dendrites of both primary and secondary motoneurons are directed mainly laterally or dorsolaterally in the cord to a region dorsolateral to the motor column where they branch and run longitudinally, rostrally and caudally $46,88,122,141$. Gap junctions are present between some of the larger dendritic processes of motoneurons in goldfish ${ }^{122}$.

Van Raamsdonk et al. ${ }^{141}$ studied the relationship between the organization of the musculature and the organization of the motor column in adult zebrafish. They labeled motoneurons innervating different portions of the axial musculature using HRP applied to the muscle. Although they provide no reconstructions of the positions of labeled cells in the motor column, their remarks indicate that when they applied HRP to the red muscle near the lateral line they labeled motoneurons only in the ventral portion of the motor column, while when they applied HRP to white muscle in the extreme dorsal portion of the myomeres they labeled motoneurons only in the dorsal portion of the motor column. The size distributions of motoneurons presented by van Raamsdonk et al. ${ }^{141}$ indicate that only smaller motoneurons innervate red muscle, while both small and large motoneurons innervate white. Myers ${ }^{89}$ filled motoneurons in both the dorsal and ventral portions of the motor column in zebrafish by applying HRP to the axial musculature of larval zebrafish that had not yet developed red muscle. His results indicate that the motoneurons innervating the white muscle are not confined to the dorsal portion of the motor column. They contradict the observations by van Raamsdonk et al., unless some reorganization of the motor column occurs in conjunction with the later development of red muscle. Studies of zebrafish also indicate that individual primary motoneurons, which can be uniquely identified because of their small number, innervate separate, mutually exclusive regions of the myomeres $^{148}$.

In goldfish, as in zebrafish, different populations of motoneurons innervate the functionally different red and white muscle (Figs. 8 and 9$)^{46}$. The red is innervated only by small motoneurons that occupy the ventral part of the motor column. Their small axons pass lateral to the Mauthner axon in the cord, and most, if not all, enter the medial rami to the red mus- 
cle. The white muscle is innervated by a population of motoneurons that does not innervate red. They are the largest, and they occupy a characteristic position in the extreme dorsal part of the motor column. All of their relatively large axons run medial to the Mauthner axon in the cord and enter the dorsal or ventral rami. White muscle is also innervated by some small motoneurons similar to those innervating red. The large motoneurons are morphologically similar to the primary motoneurons identified in embryos of zebrafish, while the smaller ones are like secondary motoneurons.

There is no relationship between the position or size of a motoneuron and the dorsoventral location of the muscle it innervates in the myomere of goldfish ${ }^{46}$.
Similar populations of motoneurons innervate epaxial and hypaxial muscle, although counts of axons in the peripheral nerves indicate that individual motoneurons probably do not innervate both. This is consistent with detailed studies of identifiable primary motoneurons in zebrafish which indicate that the primary motoneurons have distinct, non-overlapping fields of innervation in the musculature ${ }^{41,148}$.

There is little segmental overlap of motoneurons in goldfish $^{46}$ or zebrafish ${ }^{90}$. Motoneurons filled with HRP from one root are located in one segment, from the labeled root to the next rostral one $e^{46}$.

In summary, primary and secondary motoneurons in goldfish and zebrafish innervate different territories and fiber types in the myomeres. Primary ones
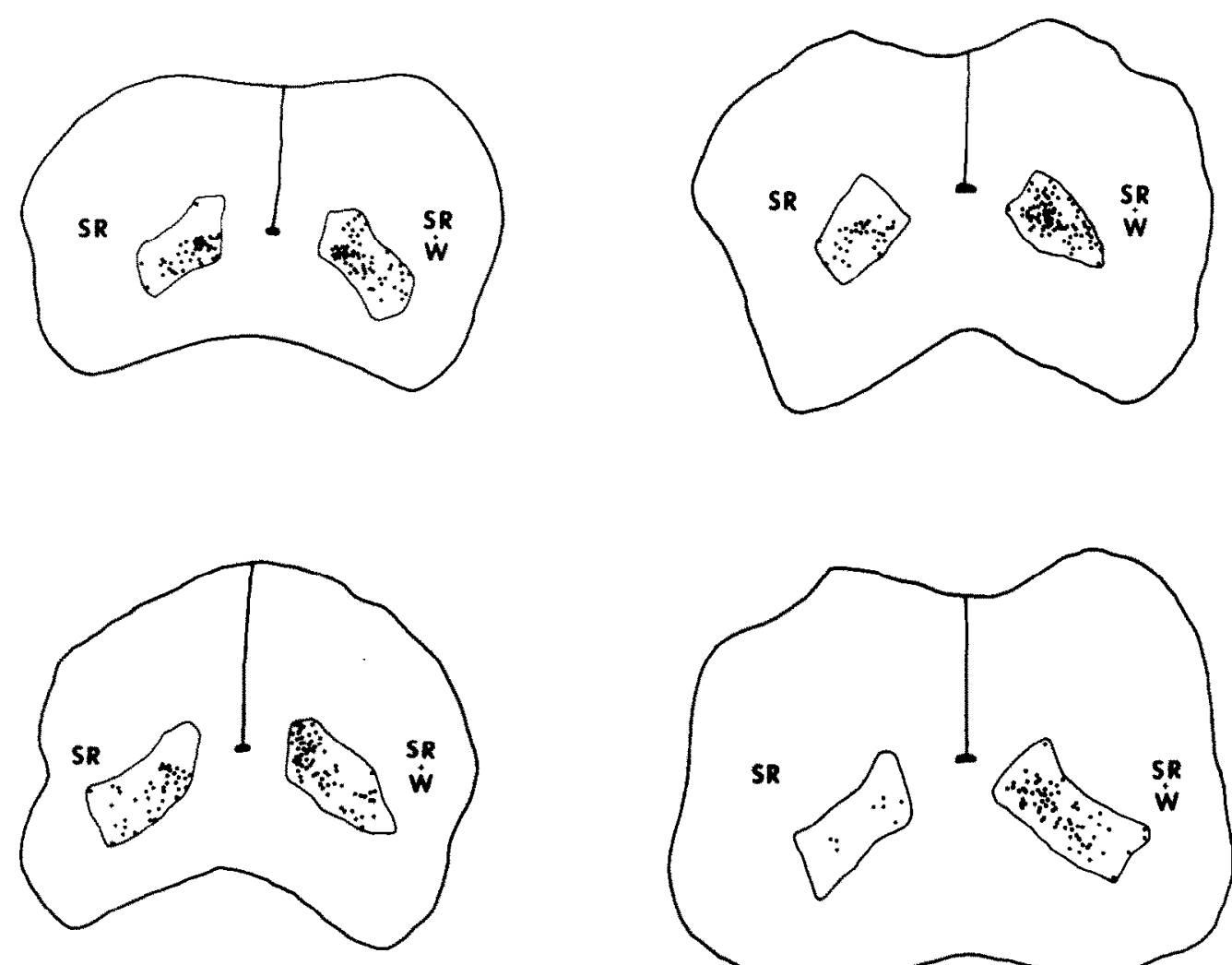

A

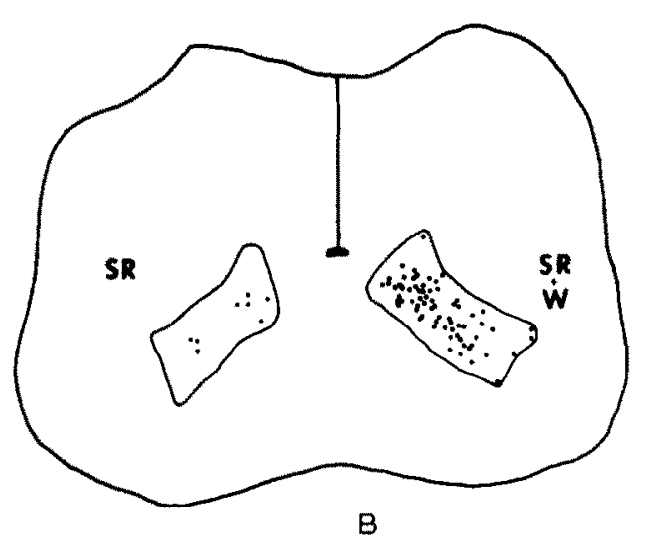

Fig. 8. Summary of the distribution of HRP-filled motoneurons in transverse sections of the spinal cord from two fish (A, B) in which both the superficial red and deep white muscle were labeled with HRP on one side of the tail (SR $+W$ ) and only the superficial red muscle was labeled on the opposite side of the tail (SR). Two summary sections are shown for each experiment. Each summary section shows the positions of HRP-filled motoneurons from a series of sections of the spinal cord. The bottom section of each pair shows the distribution of labeled cells from the rostral portion of the sections containing labeled cells, while the top sections show the distribution of more caudal cells. HRP-filled cells are represented by black dots within an outline of the medial motor column. On the side where only red muscle was labeled with HRP (SR) the labeled motoneurons are almost exclusively confined to the ventral part of the motor column. When both red and white muscle are labeled $(S R+W)$, motoneurons are filled throughout the transverse extent of the motor
column. Reproduction (ref. 46 ). 

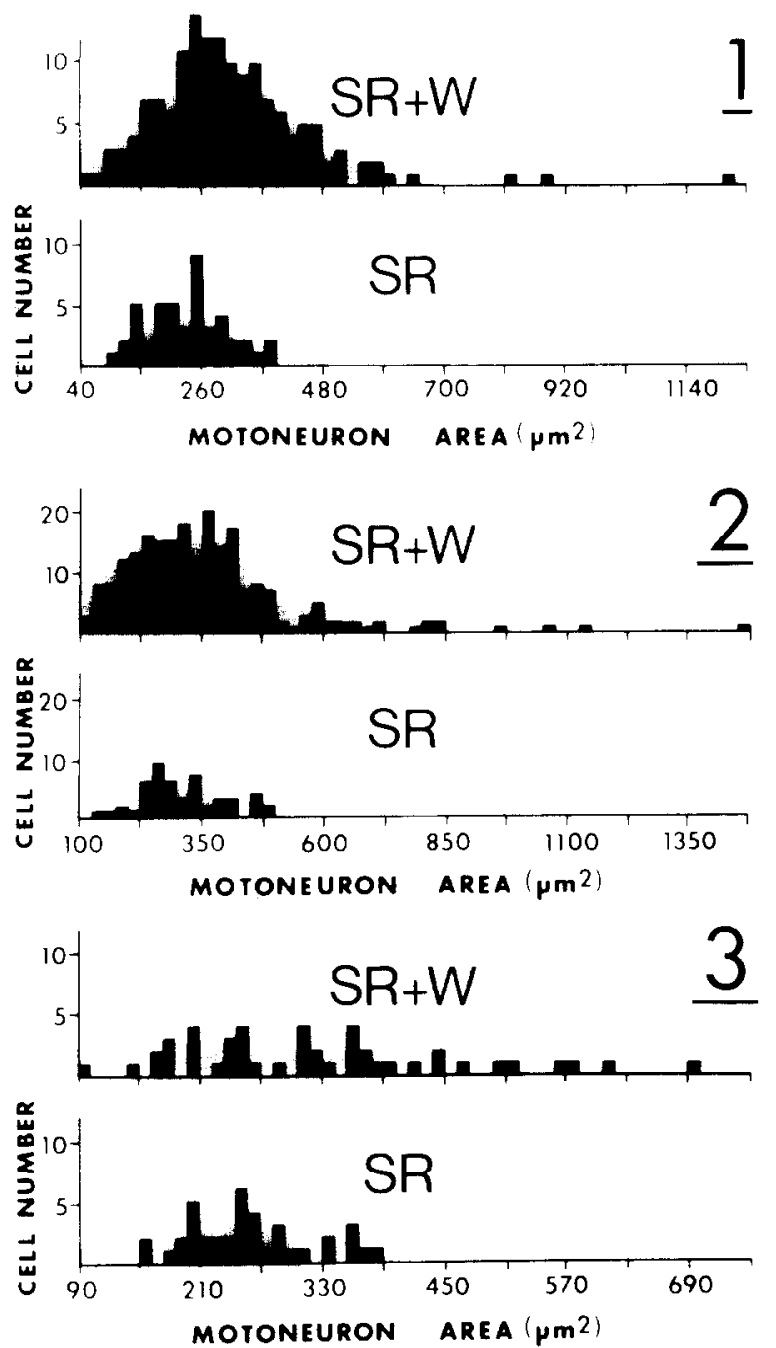

Fig. 9. The size distributions of the cross-sectional area of HRP-filled motoneurons from 3 experiments (1-3) in which both red and white muscle were labeled on one side of a fish $(\mathrm{SR}+\mathrm{W})$ and only red muscle was labeled on the opposite side of the same fish (SR). Note that the largest motoneurons in the red plus white distributions are absent when only red muscle is labeled. These largest motoneurons are those in the dorsal part of the motor column in Fig. 7C, D. Reproduction (ref. 46).

only innervate white muscle, while secondary ones innervate both red and white. In zebrafish each white fiber is innervated by a single primary motoneuron and as many as 3 secondary motoneurons. The only major difference between the two fish, beyond a difference in total number of motoneurons, is that in zebrafish the motoneurons innervating white muscle are completely segregated from those innervating red. From a functional perspective, the primary motoneurons are probably responsible for the role of the white muscle in rapid, forceful movements, just as large motoneurons are responsible for forceful movements in other vertebrates. If so, then the primary and secondary motoneurons in these fish differ with respect to their developmental histories, their morphologies, their fields of innervation, and their functional roles.

The electric organs of some electric fish (Mormyrids, Gymnotids, Gymnarchids ${ }^{36}$ ) are formed from modified axial musculature and are innervated by a specialized population of motoneurons in the spinal cord. The cell bodies of these electromotor neurons are located dorsally, near the central canal. They are relatively large (60-70 $\mu \mathrm{m}$ in Gymnarchus niloticus), electrically coupled cells without dendritic processes. They are similar in size and location to primary motoneurons in other teleost fish, and may represent evolutionary derivatives of primary motoneurons.

\section{AMPHIBIANS}

\subsection{Urodeles}

\subsubsection{Musculature}

The axial musculature of salamanders is divided into myomeres; however, there is some subdivision of the myomeres on the trunk into muscle groups similar to some of those present in amniotes. A relatively large, undifferentiated, muscle mass called the dorsalis trunci forms most of the epaxial muscle of the trunk. The dorsalis trunci is divided into myomeres by myosepta, and is generally similar to the epaxial muscle of fishes ${ }^{94,95}$. There is some differentiation of the deeper epaxial muscles associated with the vertebrae ${ }^{5}$.

The hypaxial trunk muscles are divided into 3 layers: a superficial external oblique, an internal oblique, and a transversus abdominus. The muscle fibers in each layer are oriented differently. A rectus abdominus muscle runs along the ventral midline. With a few exceptions (e.g. Proteus, Amphiuma, Salamandra), all of these hypaxial muscles are divided transversely into myomeres by connective tissue septa that penetrate through the different muscle layers and form the origin and insertion sites of the muscle fibers ${ }^{6,94,95,113}$. The axial muscle on the tail is myomeric without the differentiation of the muscle layers present on the trunk. The muscle fibers on the tail of 
Triturus lie mainly parallel to the long axis of the body; the variation in orientation of fibers found in fishes is absent ${ }^{153}$.

The muscle fibers in larval and adult urodeles are divided into at least two fiber types ${ }^{136,137,144}$. A red type forms a thin, one to two fibers thick, superficial layer just beneath the skin. The bulk of the muscle fibers are white fibers deep to the red layer. In larvae of Hynobius tokyoensis, red muscle fibers are also found intermixed with deep white fibers at the dorsoventral level of the notochord (Fig. 10B) $)^{144}$. The red fibers are smaller, have a higher succinic dehydrogenase activity, and a greater density of mitochondria than the white fibers ${ }^{136,137,144}$.

Both non-spiking, polyneuronally innervated, tonic muscle fibers, and twitch fibers are present in the extraocular muscles of urodeles ${ }^{85}$. However, I could find no physiological studies of fiber types in the trunk músculature.

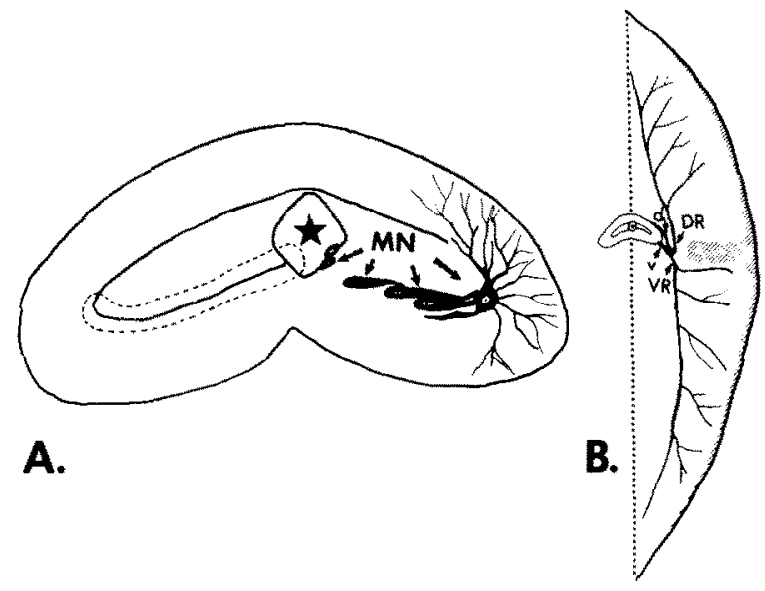

Fig. 10. Diagrammatic view of transverse sections of (A) the spinal cord and (B) the musculature in mudpuppies (Necturus maculosus) to show the motoneurons and the relationship between the spinal nerves and the musculature. A: motoneurons (MN) spreading throughout the motor column are shown on the right. The largest, multipolar motoneurons occupy the lateral tip of the gray matter, which is outlined on the left with a solid line. Motoneurons medial to these are smaller, and unipolar. Those adjacent to the ependymal layer surrounding the central canal (star) are very simple, rounded cells. The dotted line on the left roughly outlines the extent of the motor column. $B$ : shows a section of the tail with a dotted line indicating the midline and diagonal lines indicating the distribution of red muscle. The dorsal (d) and ventral (v) roots exit from the cord and join at a ganglion from which the dorsal and ventral rami (DR and VR) arise and travel in the epaxial and hypaxial musculature respectively. $A$ is based on ref. 46 , the distribution of red muscle in $B$ is based on ref. 144.

\subsubsection{Innervation}

The dorsal and ventral roots join before the major peripheral nerve branches arise. There are apparently some interspecific differences in the branching of peripheral nerves. In most descriptions, two major rami arise after the fusion of the dorsal and ventral roots (Fig. 10B). A dorsal ramus enters the epaxial muscle and a ventral ramus enters the hypaxial muscle $^{55,94,95,138}$. The branches of the two rami are more variable. In some salamanders (e.g. Necturus ${ }^{46,94,138}$ ) the patterns of subdivision of the major rami are not regular; therefore, their branches are not easily specified. In other salamanders, branches of the two major rami that innervate different portions of the epaxial and hypaxial muscle have been identified ${ }^{94,138}$. Ni$\mathrm{shi}^{94}$ recognized two branches of the dorsal ramus - a dorsomedial branch innervating the medial portion of the epaxial muscle and a dorsolateral branch innervating the lateral epaxial muscle. He suggested that the dorsolateral branch might represent the homologue of the medial ramus of fishes.

\subsubsection{Motoneurons}

The early studies of the development of the motor column of $A m b y s t o m a^{34,35,159}$ (although these studies refer to the Genus Amblystoma, the correct name is Ambystoma) have had a significant influence on subsequent interpretations of the motor columns in other anamniotic vertebrates. Coghill and Youngstrom identified two classes of motoneurons in the motor column of urodeles. The motoneurons in the first class, the primary motoneurons, were the first to develop. They were relatively large, with dendrites directed rostrally in the spinal cord and an axon in close association with the Mauthner axon. The axon arose as a collateral of a process that continued caudally in a ventral motor tract to contact the dendrites of more caudal motoneurons. This apparent interconnection of rostral motoneurons with the dendrites of more caudal ones formed the basis of a reflex chain hypothesized as the mechanism for the rostral to caudal propagation of waves of muscle contraction along the body ${ }^{35}$.

Cells in the second class, the secondary motoneurons, developed later. They were smaller, unipolar cells with dendrites in much of the dorsolateral white matter and a small axon that ran directly to the ventral root without associating with the Mauthner axon. 
Coghill and Youngstrom hypothesized that the primary motoneurons produced the 'generalized' major movements of the animal, while the secondary ones produced the 'local movements' of portions of the animal.

Much later Blight ${ }^{13}$ used Golgi preparations to study the development of motoneurons in Triturus helveticus. He recognized two types of motoneurons, with some similarities to those identified by Coghill and Youngstrom. The first motoneurons to develop were a population of large ( $25-40 \mu \mathrm{m}$ diameter) primary motoneurons with lateral dendrites in the ventral three-fourths of the ipsilateral gray and a ventral dendrite in the region of the MLF. This ventral dendrite gave rise to the axon which passed medial to the Mauthner axon and ran caudally before it exited in a ventral root. Some axons bypassed ventral roots to exit from more caudal ones. The second type of motoneuron was a smaller, unipolar cell $(15-20 \mu \mathrm{m}$ in diameter) located slightly ventral to the primary motoneurons. These cells had dendrites located in the ipsilateral, ventral white matter and a small axon running directly to the ventral root without any association with the MLF.

Similar populations of motoneurons were also identified using HRP in the paedomorphic, permanently larval mudpuppies (Necturus maculosus), although their development was not examined ${ }^{46}$. A large primary-like group with extensive dendritic arbors occupied the lateral tip of the ventral horn (Fig. 10A). Smaller, unipolar, secondary-like motoneurons were medial to these, and a few morphologically simple, possibly newly born motoneurons were located subadjacent to the ependymal layer. Motoneurons filled from HRP labeling of single ventral roots were spread over two and sometimes 3 segments in the cord; therefore some motor axons bypassed one or two ventral roots before exiting from the cord. The populations of motoneurons innervating epaxial and hypaxial muscle on the tail were largely similar (Fig. 11). Primary and secondary-like motoneurons innervated both epaxial and hypaxial muscle, although there were some slight differences in the distributions of epaxial and hypaxial motoneurons in the cord.

The presence of descending collaterals from motoneurons, like those mentioned by Coghill ${ }^{34.35}$, was evaluated directly in Necturus by applying HRP to entire ventral roots or branches of ventral roots to

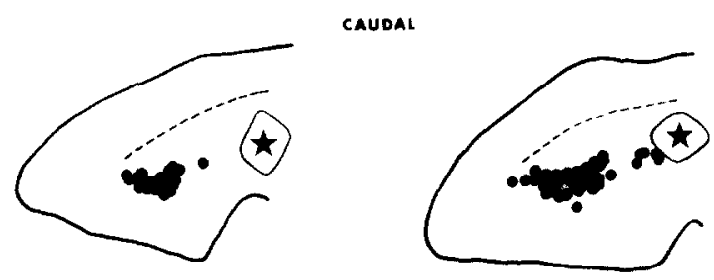

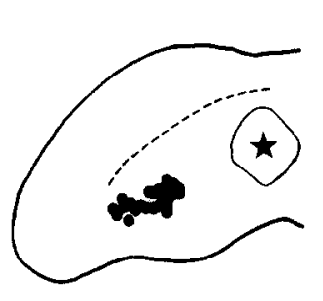

$100 \mathrm{~mm}$

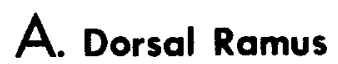

nostmal

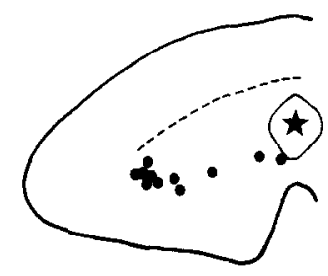

100 um

\section{B. Ventral Ramus}

Fig. 11. Reconstructions of the positions of HRP-filled cells in transverse sections of the spinal cord of mudpuppies (Necturus maculosus) after applying HRP to (A) a branch of the dorsal ramus or (B) a branch of the ventral ramus of a spinal nerve. Two summary sections are represented for each experiment. Each section shows one half of a transverse section of the cord. On the right in each section a line outlining the ependymal layer surrounds a star marking the central canal. The approximate location of the dorsal portion of the gray matter is indicated by a dashed line. The locations of HRP-filled motoneurons are shown as black dots. To produce these summary sections, the number of sections between the most rostral and the most caudal labeled cells in the cord was divided in half. Labeled motoneurons in the rostral half of the sections are plotted on the bottom summary section; those in the caudal half, on the top section. The distribution of cells filled from the dorsal and ventral rami are similar, except for the few cells located near the ependymal layer when the ventral ramus is labeled. Reproduction (ref. 46).

detect whether, following the HRP fills, any filled processes in the ventral white matter bypassed roots labeled with HRP. In $80 \%$ of the cases ( 24 of 30 ) no processes bypassed the root from which they were filled. In 6 of 30 , one to 10 processes bypassed the labeled root to exit in a more caudal one. Thus the few caudal processes that were present always exited in a more caudal root ${ }^{46}$.

These observations support those of Blight ${ }^{13}$ who also, unlike Coghill and Youngstrom, saw no descending collaterals from motoneurons in his Golgi preparations. Individual axons must have been difficult to trace in the tangle of processes visible in the silver-stained preparations used by Coghill and 
Youngstrom, and as Blight correctly pointed out, Coghill and Youngstrom probably misinterpreted the origin of the axons of the primary motoneurons. This is especially likely, because some motor axons bypass ventral roots to exit in more caudal ones (see above); in silver stains these bypassing axons might easily appear to give rise to other axons that exit in roots.

Blight suggested that the primary motoneurons might generate the early, massive, high frequency bending movements of the embryo, while the secondary ones produce low frequency movements and provide tonic support of the body. The evidence for this interpretation was: the correlation of the sequence of development of the different motor behaviors with the sequence of differentiation of the motoneurons - high frequency movements and primary motoneurons first, low frequency movements and secondary motoneurons later; the association of the large cells with the Mauthner axon, which is clearly important in the rapid, substantial movements that occur during the startle response of many anamniotes; and the observation that some of the secondary motoneurons project to regions of the myomeres occupied by red muscle fibers in other urodeles. This evidence, in combination with earlier circumstantial evidence for a functional difference between primary and secondary motoneurons ${ }^{34,35,159}$ is suggestive, but functional studies are needed to provide direct examinations of these hypotheses.

\subsection{Caecilians}

\subsubsection{Musculature}

The trunk musculature of the elongate, limbless caecilians is generally similar to the trunk musculature of urodeles. The dorsal musculature is formed mainly by a relatively undifferentiated, myomeric, dorsalis trunci. An external oblique, internal oblique, transversus and rectus abdominus make up the ventral musculature. The transversus and internal obliques are usually not divided into myomeres by connective tissue septa, while the external oblique and rectus abdominus are divided ${ }^{93,95}$.

\subsubsection{Innervation and motoneurons}

There are no recent studies dealing with the spinal nerves or motor columns of caecilians. However, a recent preliminary report ${ }^{142}$ suggests that some features of the organization of the spinal nerves may be unusual in comparison with other vertebrates because individual rostral nerves run caudally to innervate muscles spread over a large rostrocaudal extent of the body.

\subsection{Anurans}

\subsubsection{Musculature}

6.3.1.1. Larvae. The axial musculature in anuran tadpoles is myomeric. Two different types of muscle fibers are present in the myomeres on the tail. Small red fibers form a thin layer just beneath the skin. White fibers lying beneath the red ones constitute the bulk of the fibers in the myomeres ${ }^{118,119}$. Lewis and Hughes $^{80}$ show, based on cholinesterase staining, that the muscle fibers in the axial musculature of $\mathrm{Xe}$ nopus tadpoles are innervated only at their myoseptal ends. This terminal innervation is usually characteristic of spiking fibers. They may, however, have overlooked the very thin superficial layer of red fibers where one would expect fibers with nerve terminals spread over their surface.

6.3.1.2. Adult frogs. The limbs play a primary role in the locomotion of adult frogs. The axial muscle is reduced. The trunk musculature is somewhat more differentiated than in urodeles. The epaxial muscle is formed by a muscle mass that is divided transversely by $\mathrm{V}$-shaped myosepta like the dorsalis trunci in urodeles. But, unlike urodeles, the dorsalis trunci of frogs is divided longitudinally into medial and lateral portions ${ }^{95}$. The hypaxial muscles include oblique (only one), transversus and rectus muscles similar to those in urodeles, but in frogs only the rectus is divided transversely by myosepta ${ }^{95}$.

Polyneuronally innervated, non-spiking, tonic muscle fibers and spiking twitch fibers are present in the axial muscles of frogs ${ }^{53}$.

\subsubsection{Innervation-adult frogs}

Two major peripheral branches arise after the dorsal and ventral roots have joined. The dorsal ramus branches into the epaxial muscle to innervate the muscles associated with the dorsalis trunci group and the skin on the dorsal portion of the body. The ventral ramus subdivides to innervate the layers of the hypaxial muscle and the rectus abdominus ${ }^{138}$. 


\subsubsection{Motoneurons}

6.3.3.1. Larvae. Most of the studies of motoneurons innervating axial muscle in anurans have dealt with the motoneurons in tadpoles. Two different types of motoneurons have been identified ${ }^{52,67}$. $77,84,97,98,146$. A population of primary motoneurons develops first. These are relatively large multipolar cells (30-50 $\mu \mathrm{m}$ in diameter in Rana and Xenopus), with dendrites ramifying extensively throughout the lateral funiculus, commissural processes extending to the contralateral ventral cord, and relatively large axons that run around the medial side of the Mauthner axon as they approach the ventral root ${ }^{52.67}$. $84,109,140$. Intracellular recordings from motor axons indicate that they receive a monosynaptic connection from the Mauthner axon ${ }^{77}$. Typically these large axons run longitudinally in the cord for some distance before they exit in a ventral root. The axons of primary motoneurons form a small number of relatively large axons in the ventral root ${ }^{67}$. Some individual primary motoneurons project axons into two adjacent ventral roots ${ }^{109}$. Initially during development the motor axons project directly out a ventral root to an apposed myotome; the longitudinal course of the axon apparently develops later as a result of the relative displacement of the myotome and the cell body of the motoneuron ${ }^{67,146,147}$. The earliest primary motoneurons project initially into only the hypaxial musculature. Later they come to innervate epaxial muscle ${ }^{84}$.

A population of smaller, secondary motoneurons develops later than the primary ones ${ }^{52,98}$. Their dendritic arbors are smaller in both transverse and longitudinal extent than the arbors of primary motoneurons. Like the primary motoneurons the dendrites extend into the lateral funiculus; however, their dorsoventral location in the funiculus is variable, and the dendrites ramify most extensively near the surface of the cord in the peripheral portion of the lateral funiculus ${ }^{98}$. The small axons of these secondary motoneurons run directly to the ventral root without an association with the Mauthner axon.

The motoneurons innervating an individual myomere in Xenopus tadpoles are spread over 4 spinal segments, with the labeled primary motoneurons located rostral to the labeled secondary ones ${ }^{97,98}$. A maximum of 4 primary and 20 secondary motoneurons are filled by HRP applied to single myomeres at midlarval stages ${ }^{98}$. Unlike most other recent investi- gators, van Mier et al. ${ }^{140}$ apply the term secondary motoneuron only to motoneurons innervating the limbs. Consequently all of the motoneurons innervating axial musculature in their work are called primary motoneurons, including cells that are called secondary motoneurons in other studies of the same species $^{98}$.

According to Nordlander ${ }^{97}$, the axons of primary motoneurons 'sent collaterals peripherally in more than one root and most left behind a collateral which continued caudally in the ventrolateral tract'. These collaterals are apparently the only modern confirmation of the collaterals observed by Coghill and Youngstrom (see Section 6.1.3.). However, a note of caution is necessary because in the study quoted more than one segment was labeled and, given the segmental overlap, some apparent collaterals may have been separate motor axons that bypassed a root to exit in a more caudal one. In another similar study in Xenopus, axon collaterals that remained in the cord were not mentioned, although collaterals that ran caudally and exited the cord were observed ${ }^{140}$.

The relationship between the two types of motoneuron and the different muscle fiber types in the myomeres is unknown.

6.3.3.2. Adult frogs. The motoneurons innervating the axial muscles of adult frogs are located in a column ventral and medial to the motoneurons innervating limb muscles ${ }^{45,130}$. In the medial motor column of adult Rana pipiens, motoneurons filled by HRP applied to ventral roots have processes that cross the midline in the anterior commissure to contact dendrites and somata of contralateral motoneurons. Physiological observations indicate that motoneurons on opposite sides of the body (and different segments on the same side) are connected by both chemical and electrical synapses that may serve to synchronize their activity during the bilaterally symmetric jumping and swimming of frogs ${ }^{44}$. Some of the primary motoneurons innervating the trunk muscles of tadpoles persist through metamorphosis, and they apparently provide a portion of the innervation of the axial muscles in the adult frog $\mathrm{g}^{52}$.

The motoneurons innervating some individual, dorsal neck muscles (superior and inferior intertransversarius capitus, intertransversarius dorsi, and longissimus dorsi) were examined by $\mathrm{Feng}^{45}$. The motor pools of these muscles were located ventrome- 
dially in the ventral horn with no obvious segregation of the motor pools of the individual muscles.

\section{REPTILES}

\subsection{Musculature}

The most anatomically complex arrangements of axial musculature among vertebrates are found in reptiles. The trend toward differentiation of the primitive myomeric arrangement, evident in the amphibians, also occurs in reptiles. The details of the organization of the musculature in different reptilian groups have been reviewed by others ${ }^{54,95}$ and will not be reviewed here. Only the general trends in the differentiation of the musculature will be discussed.

A variety of different arrangements of musculature are present in different groups of reptiles. The epaxial musculature is typically formed by 3 longitudinal muscle groups including, from dorsomedial to ventrolateral: a transverso-spinalis, a longissimus and an iliocostalis group ${ }^{54,95}$. The arrangements of the muscles within these longitudinal groups may be relatively simple, or very complex. In some reptiles, including crocodilians, Sphenodon, and some lizards, the epaxial musculature, especially the iliocostalis group, retains a myomeric organization ${ }^{54,95}$. However, in most reptiles there is little evidence of a myomeric organization in epaxial musculature. Instead, the 3 longitudinal bundles are formed from many small muscles that interconnect vertebrae with other vertebrae and with the dorsal portion of the ribs. The dorsal musculature is especially complex among limbless lizards and snakes in which individual muscles may span numerous body segments and have tendinous connections to muscles in other longitudinal groups ${ }^{54,68,87}$.

The hypaxial muscles, like the epaxial ones, show a range of differentiation among reptiles. The differentiation of the ventral musculature seems to occur mainly by a splitting into more layers than are present in urodeles. This splitting is associated with the well-developed ribs present in most reptiles. In a simplified scheme, the muscles associated with the ribs can be divided into 3 major groups: a transversus (or subcostalis) group occupying the medial surface of the ribs, an intercostalis group interconnecting the ribs and consisting of internal intercostals (apparently derived from the internal oblique musculature) and external intercostals (derived from the external oblique musculature), and finally a group of muscles that lay on the lateral surface of the ribs and have a variety of names ${ }^{54,95,113}$. There is also a rectus abdominus and subvertebral musculature. Usually, and especially among limbless reptiles, the hypaxial muscles are subdivided further, resulting in even more layers both medial and lateral to the ribs, and in muscles interconnecting the ribs to the skin and forming intrinsic musculature of the skin. All of the muscle layers associated with the ribs also differentiate into dorsal and ventral portions in some groups of reptiles.

The arrangement of the axial musculature in turtles is unusual among reptiles because the trunk vertebrae are fused to the carapace and therefore are immobile. Most of the axial musculature is associated with the elongate neck, and the arrangement of this neck musculature is not easily comparable to the organization of axial musculature in other reptiles ${ }^{120}$. Nevertheless, Nishi ${ }^{95}$ has associated some muscles in the neck of turtles with the transverso-spinalis and longissimus groups in other reptiles.

In summary, in most groups of reptiles the simple primitive myomeric organization of musculature is obscured by both a splitting of the epaxial muscle into longitudinal bundles composed of muscles that often span several body segments, and a delamination and dorsoventral splitting of the hypaxial muscle layers into relatively small muscles that interconnect the ribs with each other and with the skin and that also form the intrinsic muscles of the skin.

Both tonic and twitch muscle fibers have been identified in the axial muscles of reptiles ${ }^{59,152}$. The tonic fibers are non-spiking, polyneuronally and multiterminally innervated fibers, while the twitch fibers are typical spiking fibers innervated at discrete, single locations on the fibers. There is some evidence for further subdivision of the twitch fiber type into slow and fast twitch fibers ${ }^{59,152}$.

The simple spatial segregation of the different fiber types in the axial musculature of most anamniotes is not evident in the axial musculature of reptiles. Individual muscles are often composed of both tonic and twitch fibers, and the different fiber types are either intermingled, or segregated from one another within the muscle, depending upon the particular muscle ${ }^{59,108,152}$. Muscle spindles are present 
within axial muscles, and the muscle fibers in the spindles are innervated by processes of motoneurons that also innervate extrafusal muscle fibers ( $\beta$-motoneurons ${ }^{33.59}$ ).

\subsection{Innervation}

Two branches, a dorsal and a ventral ramus, arise after the dorsal and ventral roots of a spinal nerve have joined. The dorsal ramus supplies the dorsal (epaxial) muscles, including the 3 main dorsal, longitudinal bundles. The ventral ramus innervates the hypaxial musculature, including all of the muscles interconnecting the ribs and the muscles associated with the ventral skin ${ }^{47.54}$.

\subsection{Motoneurons}

In those reptiles with limbs, the motoneurons occupy two columns in the ventral portion of the ventral
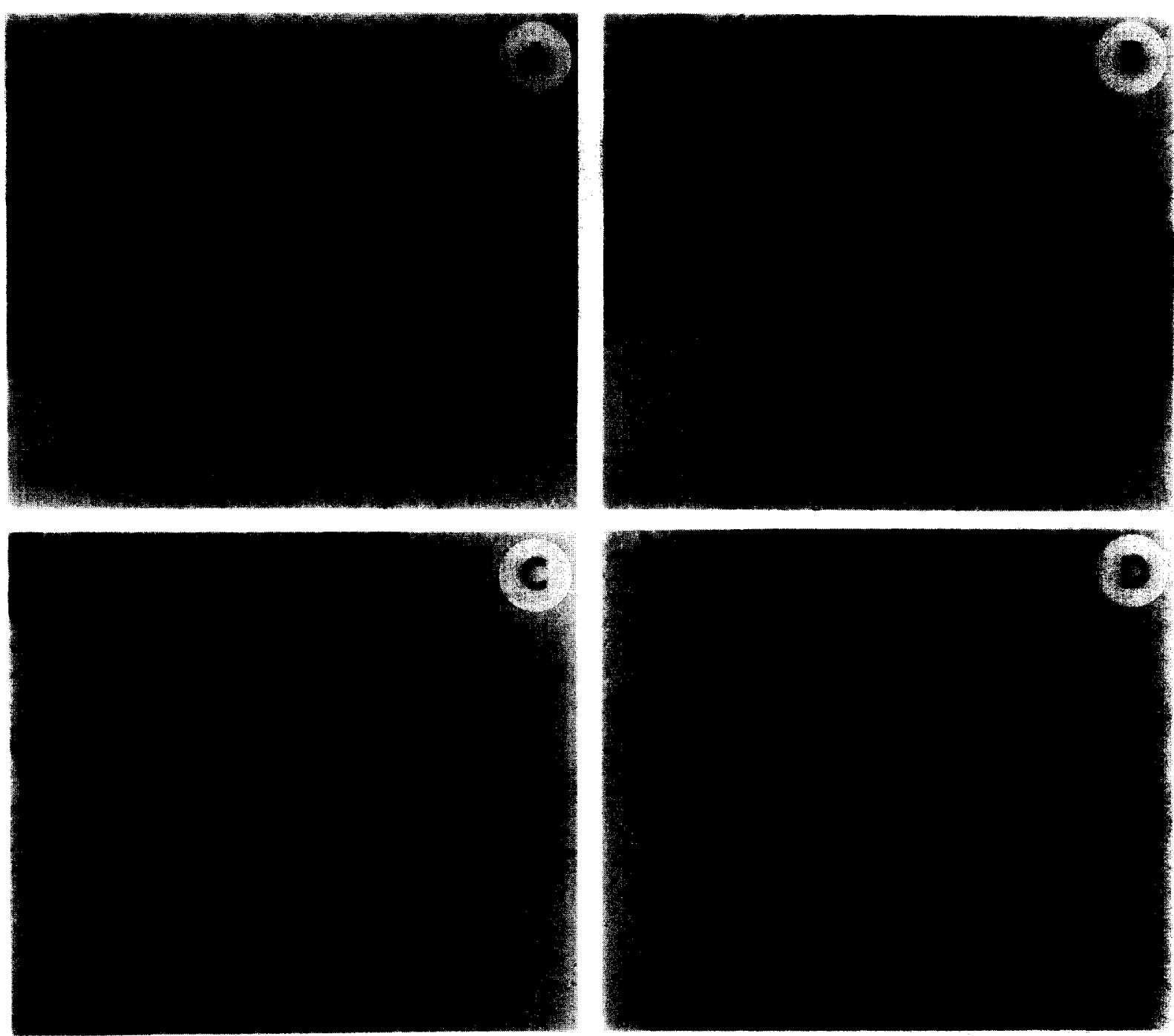

Fig. 12. HRP-filled motoneurons in the ventral horn of Florida water snakes (Nerodia fasciata pictiventris). Cross-sections of the spinal cord showing motoneurons in different regions of the ventral horn filled by HRP applied to branches of the dorsal ramus in A and B (semispinalis-spinalis and iliocostalis respectively), or branches of the ventral ramus in C and D (posterior portion of the medial branch of the ventral ramus and anterior portion of the medial branch of the ventral ramus respectively). A star is located within the central canal, and asterisks outline the ventral portion of the ventral horn. The motoneurons labeled from the dorsal ramus ( $A, B)$ are located ventromedially in the ventral horn; those labeled from the ventral ramus (C, D) are located dorsolaterally. Dendrites of some semispinalis-spinalis motoneurons (arrow in A) cross to the contralateral side of the spinal cord. Bar (A) $=50 \mu \mathrm{m}$; also applies to B-D. Reproduction (ref. 47). 
horn. A ventromedial column probably contains the motoneurons innervating axial musculature, while a ventrolateral column contains the motoneurons innervating the limbs ${ }^{75,117}$. In limbless lizards and snakes a medial motor column is located in the ventral portion of the ventral horn, and no lateral motor column is present in adults ${ }^{75}$. However, in limbless lizards a lateral motor column initially develops and then degenerates, while in snakes there is no evidence of a lateral motor column during development $^{105}$.

The only detailed study of the intrinsic organization of the motor column in a squamate reptile is a study of the medial motor column of Florida water snakes (Nerodia fasciata pictiventris) ${ }^{47}$. Motoneurons innervating axial musculature in these snakes are shown in Fig. 12. They were located in the ventral part of the ventral horn. Motor pools of different muscles occupied separate, characteristic locations in both the transverse and longitudinal extent of the motor column. Motoneurons were located near the ventral root containing their axons; most were roughly one half a segment rostral or caudal to it. Epaxial motor pools occupied the ventromedial part of the motor column and were spatially segregated from hypaxial pools which were mostly dorsolateral. Within the epaxial pools, the semispinalis-spinalis pool was medial to the longissimus and iliocostalis pools which occupied overlapping positions in the ventral tip of the ventral horn (Fig. 13). Motor pools of superficial hypaxial muscles were located in the central part of the ventral horn, and some motoneurons innervating deeper hypaxial muscles occupied the extreme dorsolateral part of the motor column (Fig. 14). The only exception to the ventromedial-dorsolateral segregation of epaxial and hypaxial pools were some motoneurons innervating the levator costae, a hypaxial muscle. These were located ventrally like some epaxial motor pools, but were segregated from them longitudinally.

The arrangement of the motor pools in these snakes was remarkably similar to the motor pools of presumed homologous muscles in rats ${ }^{125}$. The striking similarities are surprising because of the substantial differences in both the arrangement of the muscles and the locomotor kinematics in the two animals. The similarities may result from a comparable rela- tionship between the position of a motor pool and the embryonic location of the muscle it supplies (see Section 10.3.).

Yeow and Peterson ${ }^{156,157}$ used HRP to label motoneurons innervating individual muscles in the neck of a turtle (Pseudemys scripta elegans). Most muscles were innervated by single motor nuclei arranged in a musculotopic pattern, with motor pools of dorsolateral neck muscles (cervicocapitus, testocapitus, transversalis cervicis), which are innervated by the dorsal ramus of a spinal nerve, located ventromedial to motor pools of superficial ventral muscles (coracohyoideus, plastrosquamosus).

The motor pools of 3 of the muscles (retrahens capitis collique, testocervicis, longus colli) had a rather unusual organization. Each of these muscles had motoneurons located in two different motor pools - a ventral and a medial one. Motoneurons in the ventral nucleus were organized musculotopically, with testocervicis most medial and retrahens capitus collique most lateral. Motoneurons in the medial nucleus were not topographically arranged, and unlike other motoneurons, they had dendrites crossing to the opposite side of the cord. The presence of muscles having motoneurons in two separate pools is puzzling because the vast majority of axial and appendicular muscles in reptiles and mammals have discrete motor pools in the cord. In the few other cases where axial muscles were reported to have motoneurons in two separate pools the observations have been questioned by other studies, and may in some instances have resulted from unintentional leakage of HRP ${ }^{1,7,24,107.123}$ (see Section 9.3. for more details of these studies). Yeow and Peterson ${ }^{156,157}$ argue that the dual innervation they observed is not an artifact of their labeling technique and suggest that the medial nucleus is related to the generation of bilaterally synchronous activity of the muscles whose motoneurons it contained. Thus, the dually innervated muscles have a special motor pool related to bilaterally synchronous activity. This suggestion relies on inferences about the activity patterns of muscles based on both their locations in the neck and the movements made by the neck. Electromyographic observations of the activity patterns in neck muscles should eventually provide a more firm basis for this conclusion. 
A

SEMISPINALIS SPINALIS

0

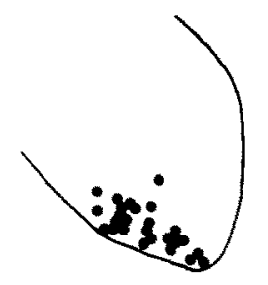

B

LONGISSIMUS

○

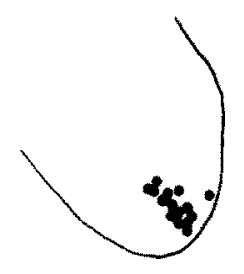

C

\section{ILIOCOSTALIS}

o

$100 \mathrm{\mu m}$

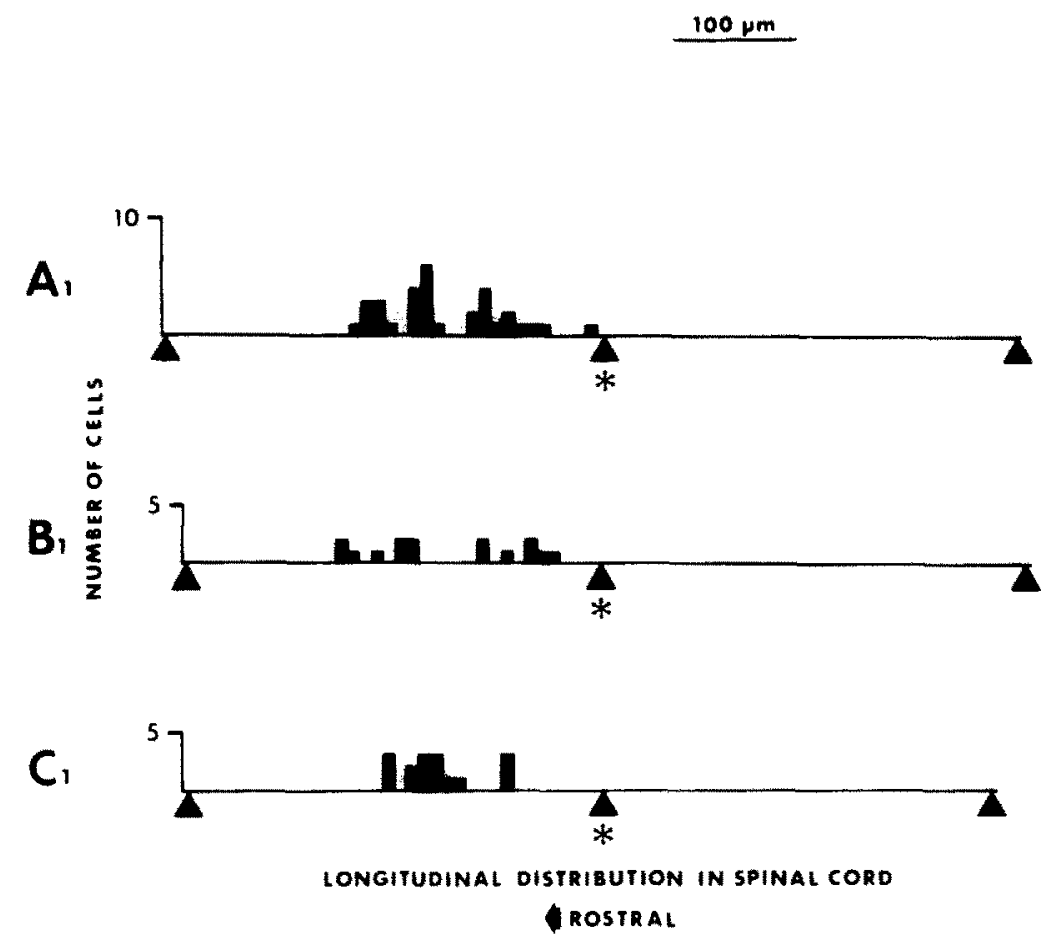

Fig. 13. Summary of the distribution of HRP-filled motoneurons in the ventral horn of Florida water snakes in which HRP was applied to branches of the dorsal ramus of a spinal nerve. A-C: show the distribution, within the transverse extent of the ventral horn, of motoneurons innervating the semispinalis-spinalis, longissimus and iliocostalis muscles. The central canal is indicated by a circle and the extent of the ventral horn is indicated by a solid line. The positions of labeled motoneurons are shown by solid black dots. The histograms at the bottom of the figure $\left(A_{1}-C_{1}\right)$ show the longitudinal distributions in the cord of the labeled cells from the experiments reconstructed in $\mathrm{A}-\mathrm{C}$. The triangles indicate the places where successive spinal nerves exit from the cord. The spinal nerve containing the labeled nerve branch in each experiment is marked with an asterisk. Each bin on the histograms represents the number of labeled cells in a distance of $80 \mu \mathrm{m}$ along the longitudinal axis of the cord. The distance between spinal nerves in different experiments varies because of variability in the size of animals. Reproduction (ref. 47).

\section{BIRDS}

\subsection{Musculature}

The dorsal trunk muscles in birds are reduced, presumably as a result of the relative immobility of the vertebral column. Anteriorly and posteriorly the axi- al muscles are involved in movements of the neck and tail. In the trunk region, two dorsal groups of muscles, a medial spinalis group and a lateral longissimus (also called an iliocostalis) are sometimes recognized $^{30,73,124}$. Nishi ${ }^{95}$ identifies muscles belonging to the 3 dorsal groups present in reptiles. Levator cos- 
VRm

0

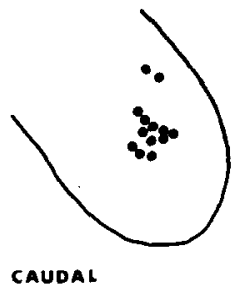

O

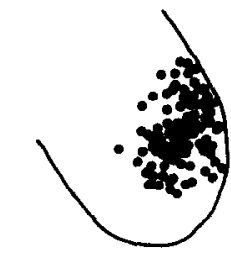

ROSTRAL

$100 \mathrm{pm}$

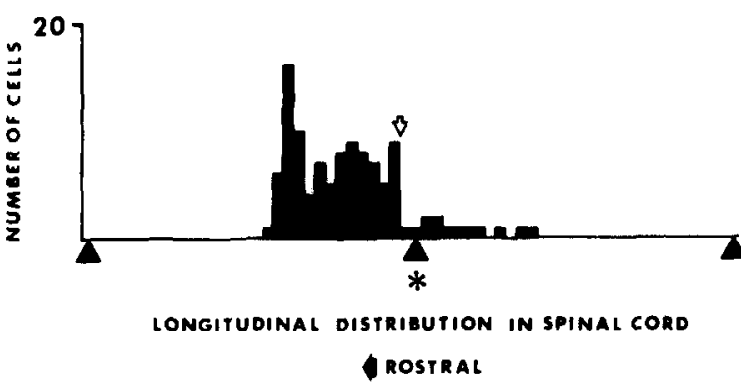

Fig. 14. The distribution of HRP-filled motoneurons after applying HRP to the medial branch of the ventral ramus of a spinal nerve in a Florida water snake. This branch innervates a majority of the hypaxial muscles in snakes. The conventions are similar to those for Fig. 13, except, because of the large number of labeled cells, two summary transverse sections are shown. To produce these drawings, the number of sections between the most rostral and the most caudal labeled cells in the spinal cord was divided in half. Cells from the rostral half of the sections are plotted in the bottom summary section, while cells from the caudal half of the sections are plotted in the top summary section. The location of the split between rostral and caudal sections is indicated by an open arrow on the histogram showing the longitudinal distribution of the labeled cells. Each bin in the histogram represents a longitudinal distance of 80 $\mu \mathrm{m}$. The motoneurons filled from this large branch of the ventral ramus are dorsolateral to those filled from the dorsal ramus, shown in the previous figure. Reproduction (ref. 47).

tae muscles are also present in birds.

The ventral muscles in the abdominal region form 3 muscle layers like those present in urodeles. In the region of the ribs, portions of the ventral muscle lay- ers form the internal and external intercostal muscles. A rectus abdominus muscle is located midventrally ${ }^{30,73,95,124}$.

The most reliable study of the embryonic origin of the axial musculature in any vertebrate was performed using chimeras formed from the axial musculature of chicks and quail ${ }^{31}$. All of the axial muscles including the dorsal and ventral muscle groups are derived from myotomes, contrary to some earlier reports that the ventral body wall muscles arise from lateral plate hypomere. The dorsal muscle of each body segment arises from the myotome associated with that segment in the embryo. Thus, replacing a portion of the chick myotomes at mid-body with quail myotomes results in dorsal musculature composed of quail muscle fibers in the region of the graft, and these quail fibers are bordered anteriorly and posteriorly by chick fibers. The intervertebral and intercostal muscles also arise from the myotome associated with the segment that they occupy in the adult. In contrast, the abdominal muscles (transversus abdominus, external oblique, internal oblique, and rectus abdominus) arise from a few somites (27-29) that spread to cover the ventral portions of the body well posterior to the segments of origin of the musculature.

Tonic and twitch muscle fibers are present in the axial muscles of birds ${ }^{63}$. Physiological studies show that the tonic muscle fibers have terminals spread over the surface of the muscle fiber, while the twitch muscle fibers are innervated at a single, well-localized position on the muscle fiber. Some muscles have a mixed population of tonic and twitch fibers, others are completely twitch or tonic ${ }^{63}$.

\subsection{Innervation}

The spinal nerves form the dorsal and ventral rami typically present in amniotes ${ }^{11,73}$. The dorsal rami supply the muscles of the back while the ventral rami innervate the intercostal and abdominal muscles ${ }^{11}$.

\subsection{Motoneurons}

The motoneurons form two columns in the ventral horn of the spinal cord. A ventrolateral column contains the motoneurons innervating the $\operatorname{limb}^{64,76}$. A group of motoneurons that presumably innervates axial muscles lies medially in the ventral horn. $\mathrm{Al}$ though the organization of the motoneurons inner- 
vating the limb muscles of birds has been studied in detail $^{64.76 .129}$ there are no studies of the relationship between the motoneurons in the medial motor column and the axial muscles. This is surprising given the detailed information about the embryonic origin of the muscles, which should provide a strong basis for evaluating relationships between the locations of motor pools and the embryonic origins of the muscles they innervate. Some muscles in chicks migrate substantial distances from their myotome of origin ${ }^{31}$ : is the location of their motor pool related to the embryonic origin of the muscle as in other amniotes, or instead to the location or function of the muscle in the adult?

\section{MAMMALS}

\subsection{Musculature}

The details of the arrangements of the axial muscles in different mammalian groups have been reviewed by Nishi ${ }^{95}$. Only the major features of the axial muscles will be dealt with here.

The major subdivisions of the axial musculature in mammals are shown in Fig. 15. They are generally similar to those present in quadrupedal reptiles. The epaxial musculature is divided longitudinally into 3 muscle groups: a dorsomedial transverso-spinalis, a longissimus and an iliocostalis group. The separation of the 3 groups is most evident in the thoracic region; the longissimus and iliocostalis muscles often join to form a single bundle in the lumbar region ${ }^{25,95,104.125}$. The iliocostalis in monotremes retains a segmental organization ${ }^{95}$. In the region of the neck, the longissimus group forms the splenius and longissimus capitus while the transverso-spinalis forms the biventer cervicis and complexus ${ }^{104}$. Levator costae muscles are associated with the dorsal portions of the ribs.

The hypaxial muscle in the abdominal region forms 3 layers (external oblique, internal oblique, transversus abdominus) similar to those present in urodeles and birds. As in reptiles, the muscles of the body wall are differentiated in the thoracic region to form the muscles associated with the ribs. Thus, in this region there are muscles superficial to the ribs (external oblique muscles), muscles between the ribs (external and internal intercostals), and muscles deep to the ribs (subcostalis or transversus muscles $)^{95,113}$. A serratus dorsalis muscle covers most of

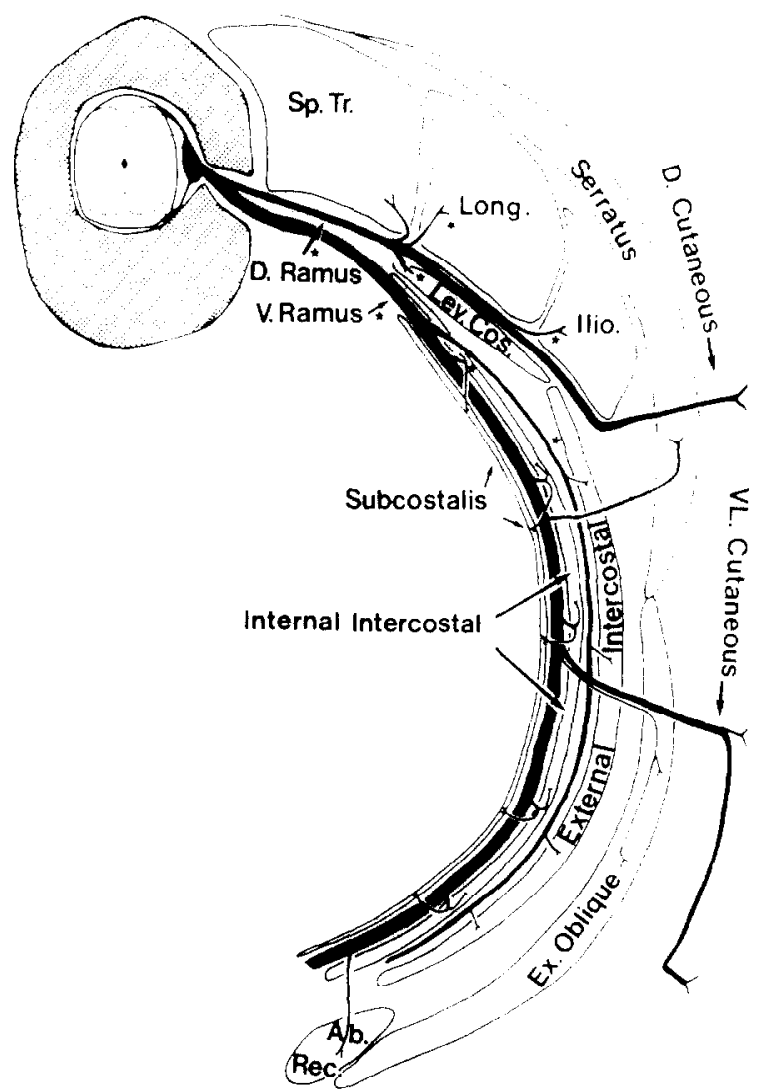

Fig. 15. Diagrammatic cross-section of a caudal thoracic body segment of a rat, showing the innervation of the axial muscles by branches of the dorsal (D. Ramus) and ventral (V. Ramus) rami of a spinal nerve. $\mathrm{D}$, dorsal; $\mathrm{V}$, ventral; $\mathrm{VL}$, ventrolateral; Ex, external; Ab. Rec., abdominal rectus; Ilio, iliocostalis; Lev. Cos., Levator costae; Long., longissimus; Sp. Tr., transverso-spinalis (muscle group). Reproduction (ref. 125) with permission from Alan R. Liss.

the rostral portion of the dorsal musculature. A rectus abdominus extends along the ventral midline.

The muscle fibers in mammalian axial muscles can be divided into at least 3 fiber types: slow twitch, fast twitch oxidative and glycolytic, and fast twitch glycolytic (also identified as types I, IIA, IIB by some authors; reviewed in ref. 27). The histochemical and physiological properties of these fiber types differ. As the names suggest, the fast twitch glycolytic fibers are involved in strong, rapid movements involving anaerobic metabolism, while the slow twitch fibers are responsible for sustained movements and the maintenance of posture, and depend on oxidative metabolism. Some muscles are composed of a variety of fiber types; others contain only a single type ${ }^{27}$. All 3 fiber types generate action potentials. True non- 
spiking tonic fibers are found only in the eye muscles and the middle ear muscles of mammals ${ }^{63}$.

\subsection{Innervation}

The dorsal and ventral spinal roots join and then give rise to a dorsal and a ventral ramus which innervate the axial muscles (Fig. 15). The dorsal ramus innervates epaxial muscles including the transversospinalis, longissimus, iliocostalis and levator costae muscles. The ventral ramus innervates hypaxial muscles including the obliques, intercostals, transversus abdominus, rectus abdominus and serratus dorsalis muscles $^{125}$.

\subsection{Motoneurons}

The motoneurons innervating axial muscles in mammals have been studied in rats (neck muscles $^{23,128}$; lumbar epaxial muscles ${ }^{24}$; thoracic muscles $^{125}$ ) and cats (neck muscles ${ }^{1,7,101.107}$ ). The studies of the motoneurons innervating neck muscles indicate that there may be differences in the organization of motoneurons innervating presumed homologous muscles in the necks of rats and cats. In cats ${ }^{107}$, the motoneurons innervating the splenius, biventer cervicis and complexus muscles were distributed in the ventromedial, spinal accessory, commissural and centrodorsal cervical motor nuclei, located ventrally in the medial and central portions of the ventral horn. In rats ${ }^{23,128}$, the motoneurons innervating the same muscles occupied only the ventromedial nucleus, with the motoneurons innervating the splenius located dorsal to the motoneurons innervating the biventer cervicis and complexus. Although these may represent real species differences, Richmond et al. ${ }^{107}$ experienced problems with leakage of HRP, and the wider distribution of motoneurons they observed may have resulted from this leakage. Furthermore, Brichta and Peterson ${ }^{23}$ found that the motoneurons innervating muscles near the splenius, biventer cervicis and complexus (i.e. sternomastoid, cleidomastoid, cleidotrapezius) are located in those regions of the motor column where Richmond et al. found labeled motoneurons not seen by Brichta and Peterson.

There are other contradictory reports dealing with the motor pools of neck muscles in cats. Bakker et al. ${ }^{7}$ report that motoneurons innervating the rectus capitus group and obliquus capitus caudalis are dis- tributed in 3 regions of the ventral horn: the ventromedial nucleus, the commissural nucleus, and the lateral margin of the ventral horn. These observations contradict an earlier observation that the motor pools of the same muscles in the same species were confined to the ventromedial nucleus ${ }^{101}$. As a consequence of these contradictions the arrangement of these neck motor pools remains unclear.

Smith and Hollyday ${ }^{125}$ performed the most complete study of the motoneurons innervating axial musculature in a mammal. They mapped the location across the transverse extent of the motor column, of the motoneurons innervating all of the major groups of thoracic muscles in rats. The motoneurons innervating most individual muscles were located in discrete motor nuclei occupying characteristic locations in the motor column. Motoneurons innervating epaxial muscles (transverso-spinalis, longissimus, iliocostalis) were located in the ventromedial portion of the ventral horn, largely segregated from the motoneurons innervating hypaxial muscles, which were dorsolateral (Fig. 16). The transverso-spinalis motoneurons were located medial to the motoneurons innervating the longissimus and iliocostalis. The motoneu-

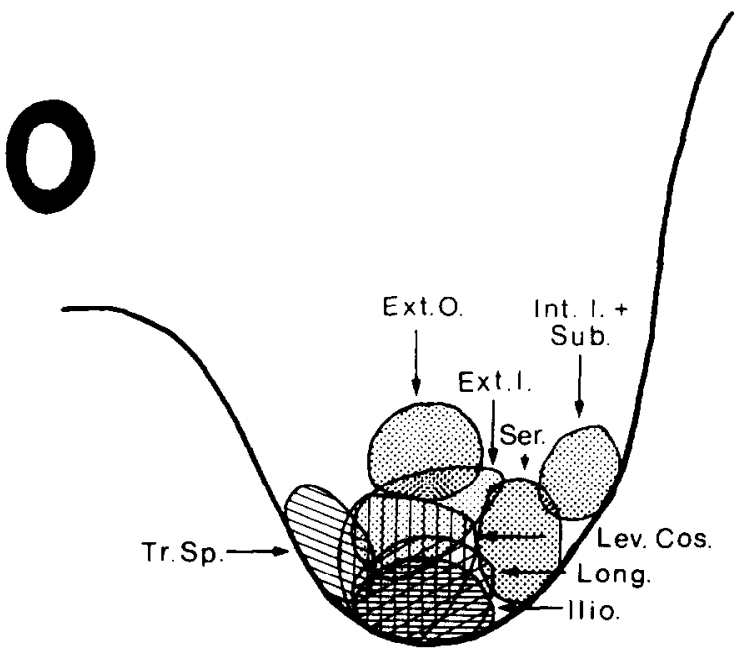

Fig. 16. Summary diagram of the arrangement of thoracic motor pools in a diagrammatic cross-section through the ventral horn of the spinal cord in a rat. Dorsal ramus motor nuclei are indicated by hatched lines, ventral ramus motor nuclei by stippling. Ext. O., external oblique; Ext. I., external intercostal; Ilio., iliocostalis; Int. I., internal intercostal; Lev. Cos., levator costae; Long., longissimus; Ser., caudal serratis; Sub., subcostalis; Tr. Sp., Transverso-spinalis. Reproduction (ref. 125) with permission from Alan R. Liss. 
rons innervating the longissimus, iliocostalis and levator costae muscles occupied overlapping positions in the transverse extent of the motor column. Motor pools of superficial hypaxial muscles (external oblique, external intercostals) were located in the central portion of the ventral horn, with the motoneurons innervating the external oblique muscles dorsal to those innervating the external intercostals. Motor pools of deeper hypaxial muscles (internal intercostals and subcostalis) were located lateral to those of superficial muscles.

The general pattern emerging from their study was consistent with a relationship between the position of motoneurons in the motor column and the place of origin, from within the myotome, of the muscle they innervate $^{125}$. Motoneurons innervating muscles arising from adjacent positions in the myotome were located in adjacent positions in the spinal cord. This topographic relationship between motor column and myotome was also evident in embryos, suggesting that motoneurons project topographically to muscle even at the earliest stages of development.

The motoneurons filled from a single ventral root were distributed along the rostrocaudal axis of the cord from two-thirds of the distance to the next rostral ventral root to one third of the distance to the next caudal one. The longitudinal distribution of motoneurons innervating different axial muscles was not examined by Smith and Hollyday ${ }^{125}$. As they acknowledge, some of the overlap of motor nuclei they observed might be spurious if motor pools that appear to overlap in the transverse extent of the motor column in fact occupy different longitudinal positions in the cord. If so, this would agree with the observation in water snakes that some motor pools of axial muscles occupy similar positions in the transverse extent of the cord, but are segregated from one another longitudinally ${ }^{47}$.

The motoneurons innervating lumbar epaxial muscles in rats ${ }^{24}$ generally occupied locations in the transverse extent of the motor column similar to the motor pools of the same muscle groups in thoracic regions $^{125}$. However, there were minor differences between the lumbar and thoracic regions. In both of these studies the authors indicated that leakage of HRP was a problem; this leakage may account for the differences in their results.

Some changes in the relative positions of motoneu- rons innervating muscles derived from the dorsal muscle groups seem to occur in the neck region of rats because the motoneurons innervating muscles derived from the transverso-spinalis group (biventer cervicis, complexus) are located ventral, rather than medial, to the motoneurons innervating muscles derived from the longissimus group (splenius) ${ }^{23.104}$. Nevertheless, the motoneurons innervating these epaxial muscles are still confined to or concentrated in the medial region of the ventral horn ${ }^{7,23.107}$.

Sprague $^{126}$ used the chromatolysis technique to study the motoneurons innervating axial muscles in rhesus monkeys. The locations of the motoneurons innervating epaxial and hypaxial muscles in the thoracic region overlapped extensively in the transverse extent of the ventral horn, but in the region of the limbs epaxial motoneurons were located ventromedial to hypaxial ones, similar to the thoracic region in rats $^{125}$. In the reconstructions illustrated by Sprague there is some concentration of epaxial motoneurons in the ventromedial portion of the motor column even in thoracic regions; the overlap he observed might be a consequence of the relatively poor resolution of the chromatolysis technique.

In mammals, the intrafusal muscle fibers in the muscle spindles are usually innervated by separate $\gamma$ motoneurons. These motoneurons are smaller than the $\alpha$-motoneurons and are intermingled among them in the motor nucleus of each muscle ${ }^{27.125}$

The motoneurons innervating different muscle fiber types are generally not segregated from one another in the motor columns ${ }^{27}$. However, there may be some segregation of motoneurons innervating different muscle fiber types in the neck muscles of rats $^{23}$.

\section{OVERVIEW}

\subsection{Musculature}

The axial musculature of most anamniotes is morphologically similar in several respects, and these presumably reflect primitive features of the axial musculature of vertebrates. The musculature is myomeric. The myomeres are folded to a variable extent, but usually are not subdivided into the anatomically discrete muscles seen in most amniotes. At least two, and in many cases more than two fiber types are present in the myomeres. A non-spiking, tonic, red fiber 
type and a spiking, twitch, white type are always evident and are usually spatially segregated in the myomeres with the tonic fibers generally superficial to the twitch.

This primitive arrangement of axial musculature is modified in several ways among amniotes. The most dramatic change is the breakup of the myomeres into a number of discrete muscles with separate origins and insertions on the vertebrae and ribs. The extent of the myomeric reorganization varies; it is greatest among limbless reptiles and is less dramatic in amniotes with limbs. Many of the myomeric derivatives are still involved in locomotion as in fishes. Some, however, are associated with the lungs and ribs, playing roles in ventilation formerly filled by the branchiomeric muscles associated with the gills in fishes.

The breakup of the myomeres is correlated with a loss of the spatial segregation of the different fiber types. Individual axial muscles in amniotes usually contain different fiber types, and these are often intermingled in the muscle. Tonic fibers are retained in some muscles of reptiles and birds, but are absent in axial muscles of mammals.

In summary, there is a trend toward increasing complexity, from a primitive, simple myomeric organization with spatially segregated fiber types to an array of discrete muscles, each containing different fiber types that may be intermingled in the muscles. This increasing complexity of muscles is at odds with the notion that axial muscles were relegated to a secondary role after the development of limbs. It is, however, consistent with both the new role of some of these muscles in ventilation and the increasing importance attached to their roles in support and locomotion among amniotic vertebrates $28,43,135,160$.

\subsection{Innervation}

Although the increasing differentiation of axial muscles among vertebrates has been acknowledged for some time, in the past the innervation of the muscles, or more specifically the branching patterns of the spinal nerves, was viewed as conservative. The fields of innervation of branches of spinal nerves have served as the primary basis for determining the homologies of the major groups of axial muscles among vertebrates. Usually, discussions of the evolution of the axial musculature depend upon the assumption that the spinal nerves supplying axial mus- cles in all gnathostomes consist of only two major branches - a dorsal ramus innervating epaxial muscles and its derivatives and a ventral ramus supplying hypaxial muscles and its derivatives ${ }^{54,99,113}$.

This overly simplistic interpretation of spinal nerves and muscle homologies is now suspect at two levels. Studies of teleosts show that the assumption that all gnathostomes have only two major branches of spinal nerves that innervate epaxial and hypaxial muscles respectively, is erroneous. In catfish and in goldfish ${ }^{8,46}$ there are 3 major rami, and one of these, the medial ramus, innervates both epaxial and hypaxial muscle. A systematic study of spinal nerves is necessary to evaluate whether this is the primitive arrangement in vertebrates or a unique arrangement found only in some teleosts. If this is the primitive pattern, then there is not a simple one to one correspondence between the spinal nerve branches in fishes and those in amniotes; this would substantially complicate the evaluation of homologies between the two groups.

Even if comparable nerve branches are identified in different groups, the determination of homologies may still be difficult because of observations, discussed further below, which indicate that branches of spinal nerves formerly thought to be homologous in different vertebrates (the dorsal and ventral rami that innervate presumptive epaxial and hypaxial muscle respectively) contain axons from different populations of motoneurons.

\subsection{Motoneurons}

10.3.1. Anamniotes. The functional subdivision of the musculature that is so basic to the motor systems of anamniotes is reflected centrally in the organization of the motoneurons in the motor column. The populations of motoneurons innervating red (tonic) and white (twitch) fibers differ in size (the white are larger), distribution of their somata and dendrites in the cord, and the pathways taken by their axons to the periphery. There is also evidence that they differ developmentally; the primary motoneurons, which innervate exclusively white muscle, differentiate earlier than the motoneurons innervating red. Thus differences in the location, morphology, and developmental history of motoneurons are correlated with differences in the functionally different fiber types they innervate. 
The link between the organization of the musculature and the motor column is most clear in some teleost fish and lampreys, for which the most data are available. However, there is some evidence that suggests other anamniotes may be similar. Different, spatially segregated motoneurons innervate different fiber types in cartilaginous fish. Urodeles and anuran tadpoles have primary and secondary motoneurons like those in teleost fish; and physiological, behavioral and morphological pieces of evidence suggest that these motoneurons have different functional roles and may innervate different fiber types.

The topographic relationship, evident in amniotes, between the location of a motoneuron in the motor column and the location of the muscle it innervates in the dorsoventral extent of the myotome has not been found in the few anamniotes that have been studied. In goldfish and lampreys the motoneurons innervating different dorsoventral locations in the myomeres are intermingled in the motor column. However, individual motoneurons do not innervate both epaxial and hypaxial muscle, and differences in the dendritic arbors of epaxial and hypaxial motoneurons in lampreys suggest they may at times receive different inputs. Nevertheless, given the predominance of lateral bending in the propulsion of aquatic anamniotes, and the coactivation of epaxial and hypaxial muscle required for such bending, the absence of striking differences between epaxial and hypaxial motoneurons is understandable.

Although the evidence suggests that a series of features are shared by the motor columns of many anamniotes, only a few species have been studied systematically. Consequently, it is difficult at this point to evaluate whether most of the features are primitive or derived in any particular species. Primary and secondary populations of motoneurons are present in many groups. While they may have been independently derived a number of times, most probably they are shared due to common ancestry. The association of primary and secondary motoneurons with different fiber types is best established in teleost fish. There is circumstantial evidence that they may innervate different fiber types in other anamniotes, but more studies are required both to confirm this and to establish whether the correlations among the morphology, developmental history, and motor unittype of motoneurons are primitive characteristics of the motor column in vertebrates.

The absence of any obvious topographic relationship between the location of motoneurons and the dorsoventral location of the muscle they innervate in the myomeres is evident in lampreys, goldfish and mudpuppies. More species must he examined to determine if this is the primitive condition among vertebrates, although the similarities shared among these phylogenetically disparate animals suggest that it is. This information is of course essential for understanding the evolution of the striking topography present in some amniotes.

10.3.2. Amniotes. The breakup of the primitive myomeric musculature among amniotes is correlated with a subdivision of the motor column into discrete motor pools serving the individual muscles arising from the myomeres. These motor pools are organized topographically; epaxial pools are segregated from hypaxial ones, and within the epaxial and hypaxial pools the location of the motoneurons innervating any particular muscle is related to the location of the precursor of the muscle in the embryonic muscle masses. Thus there is a topographic map of position in the motor column onto position in the embryonic myotome; adjacent motor pools innervate muscles arising from adjacent positions in the myotome. This topographic arrangement of the motor column is dramatically different from the motor column in the anamniotes that have been studied. In the latter, the epaxial motoneurons are not segregated from hypaxial ones, and there is little evidence of a map of the motor column onto the myomeres.

The presence of these two patterns of organization in the motor columns of different vertebrates which at one time shared a common ancestor - implies that the medial motor column has undergone a major reorganization during the evolution of vertebrates. Although this reorganization has clearly occurred, the direction of the evolutionary change is problematic because relatively few species have been studied. At this point, a simple motor column/myotome map like that in rats and snakes is not evident in species of anamniotes representing several major groups (agnathans, teleost fish and urodeles), which suggests that such a topography was also absent in the early vertebrates. Otherwise we must postulate the independent evolution of a comparable organization in several different lines. If this somewhat pre- 
mature assessment is correct, then the evolutionary transition was from non-topography to topography, and a motor column/myotome map must have arisen at some time during the evolution of vertebrates. A test of this hypothesis will come from further studies of anamniotes representing groups not yet examined.

While the differences between amniotes and anamniotes are striking, suggesting a very malleable motor column, equally striking are the remarkable similarities between such phylogenetically, morphologically and functionally different amniotes as rats and snakes. These similarities have several major implications for the organization and evolution of the motor column. The differences in the locomotion of rats and snakes are obvious and substantial. Yet the changes in their motor systems that accompany these functional differences have occurred without any fundamental reorganization of the motoneurons in the motor column. Clearly the detailed arrangement of the motor pools need not reflect the functional organization of the motor system. This conclusion is also supported by studies of limb and eye musculature ${ }^{57.76}$. All of these studies indicate that motor systems sometimes evolve through modifications of the central circuitry without any reorganization of the motor pools.

The motor columns in water snakes and rats may be similar either because these animals share the arrangement present in their common ancestor or because they independently acquired similar motor columns. Similarity per se does not indicate common ancestry, but certain features in this particular case lend support to common ancestry as the more likely explanation. First, the similarities are striking, not only in the segregation of epaxial and hypaxial pools, but also in the locations of the motor pools of separate epaxial and hypaxial muscles. If these arrangements were independently derived, then we must imagine the independent evolution of the same, detailed topography of motor pools, something that seems unlikely. Furthermore, the independent acquisition of characters is usually attributed to the presence of common selective pressures in different groups. The source of these common selective pressures in such functionally and ecologically disparate animals as rats and snakes is difficult to imagine. The evidence for a similar segregation of epaxial and hypaxial mo- tor pools in rhesus monkeys and some neck muscles of turtles also suggests an early origin of the pattern among amniotes.

If the similarities between rats and snakes are the result of common ancestry, then some predictions follow. The common ancestor of rats and snakes is close to the common ancestor of all amniotic vertebrates. Therefore, the topographic arrangement of the motor column in rats and snakes must have arisen prior to, or in conjunction with the origin of the major groups of amniotes. This topography must then have been conserved in the face of the major structural and functional changes occurring during the evolution of snakes and rats. If the arrangement of the motor column remained unchanged during the evolution of these very different amniotes, we might predict that it would be conserved in other amniotes as well. Thus, if common ancestry is the explanation for the similarities between rats and snakes then we would expect that birds, quadrupedal reptiles, and other mammals should have medial motor columns arranged like those in rats and snakes. The strongest test of the common ancestry hypothesis will be studies of the motor columns in these other amniotes.

Whatever its origin, the acquisition of a simple topographic relationship between motor column and myotome in the embryo has apparently played a significant role in the phylogenetic history of the medial motor column. An important consequence of such an embryonic topography is that once such a relationship is present the subdivision of the embryonic muscle masses during development or evolutionary history produces muscles with separate, localized motor pools no matter how that subdivision takes place, as long as it is a simple breakup of the muscle masses without intermingling of different regions. Functionally different muscles in many different motor systems nearly always have separate motor pools ${ }^{32}$. 47,57,64.76.82.83.121.125.129.151, and this correlation suggests that separate motor pools are very important for the proper control of functionally different muscles. The presence of an embryonic topography assures that separate muscles arising from the myotomes have separate motor pools in the cord, and thus may have facilitated the evolution and control of the more complex arrangements of axial muscles in amniotes. 


\section{SUMMARY}

In most anamniotes the axial musculature is myomeric and is functionally subdivided into superficial red and deep white muscle. In those anamniotes that have been studied the organization of the motor column is related to this functional subdivision. The motoneurons innervating red and white muscie differ in size, distribution in the motor column, and developmental history. There is no obvious topographic relationship between the location of motoneurons in the motor column and the dorsoventral location of the muscle they innervate in the myomeres; epaxial motoneurons are not segregated from hypaxial ones.

Among amniotes, the myomeres divide to form a number of discrete muscles that may be complexly arranged. This breakup of the musculature is correlated with a subdivision of the motor column into discrete motor pools serving the different muscles. Unlike anamniotes, the motor pools are topographically organized. The epaxial pools are segregated from hypaxial ones, and within the epaxial and hypaxial pools the location of motoneurons innervating any particular muscle is related to the location of the muscle's precursor in the embryonic muscle masses. Thus adjacent motor pools innervate muscles arising from adjacent positions in the myotome.

These dramatic differences between the motor columns in anamniotes and amniotes imply that the medial motor column has undergone a major restructuring during the evolution of vertebrates. The available

\section{REFERENCES}

1 Abrahams, V.C. and Keane, J., Contralateral, midline, and commissural motoneurons of neck muscles: a retrograde HRP study in the cat, J. Comp. Neurol., 223 (1984) 448-456.

2 Alexander, R.M., The orientation of muscle fibers in the myomeres of fishes, J. Mar. Biol. Ass. U.K., 49 (1969) $263-290$.

3 Altringham, J.O. and Johnston, I.A., Quantitative histochemical studies of the peripheral innervation of $\operatorname{cod}(\mathrm{Ga}$ dus morhua) fast myotomal muscle fibers, J. Comp. Physiol., 143 (1981) 123-127.

4 Andersen, P., Jansen, J.K.S. and Løyning, Y., Slow and fast muscle fibres in the Atlantic hagfish, Myxine glutinosa, Acta Physiol. Scand., 57 (1963) 167-179.

5 Auffenberg, W., The epaxial musculature of Siren, Amphiuma, and Necturus (Amphibia), Bull. Flor. St. Mus. Biol. Sci., 4 (1959) 253-256. evidence - which is tentative because of the few species that have been studied - suggests that a topographically organized motor column was absent in early vertebrates. A motor column/myotome map appears to have arisen just prior to, or in conjunction with the origin of amniotic vertebrates. The details of this map were conserved in different amniotes in spite of major structural and functional changes in the musculature. The map may be important for the proper control of the many muscles arising from the myotomes in amniotes because it facilitates the development and evolution of motor systems in which anatomically and functionally different muscles have spatially separate motor pools in the cord.

\section{ACKNOWLEDGEMENTS}

I thank Dr. Stephen S. Easter Jr. for his support during the preparation of this review and for his comments on the manuscript. I also thank Drs. Fred Carey and Steven Scherer for many discussions related to the ideas presented here. Mr. David Carrier and Drs. David Cundall, R. Glenn Northcutt, Bruce Oakley, Peter Pridmore, Pamela Raymond, Thomas Scanlon and Steven Scherer also provided comments on various versions of this manuscript. Financial support was provided by an NSF Predoctoral Fellowship, by an NIH Postdoctoral Fellowship, by the Division of Biological Sciences at The University of Michigan, and by NIH Grant EY00168 to Dr. Stephen S. Easter Jr.

6 Auffenberg, W., A review of the trunk musculature in the limbless land vertebrates, Am. Zool., 2 (1962) 183-190.

7 Bakker, D.A., Richmond, F.J.R. and Abrahams, V.C., Central projections from cat suboccipital muscles: a study using transganglionic transport of horseradish peroxidase, J. Comp. Neurol., 228 (1984) 409-421.

8 Barets, A., Contribution a l'étude des systèms moteurs «lent" et «rapide» du muscle latéral des téléostéens, Arch. Anat. Microsc. Morphol. Exp., 50 (1961) 91-187.

9 Barrington, E.J.W., Essential features of lower types. In M.H. Wake (Ed.), Hyman's Comparative Vertebrate Anatomy, University of Chicago press, Chicago, 1979, pp. $57-86$.

10 Beccari, N., Peculiari modalità nelle connessioni di alcuni neuroni del sistema nervoso centrale dei Pesci. Ultcriori ricerche sulle collaterali delle fibre del Mauthner, Arch. Ital. Anat., 17 (1919/1920) 239-283.

11 Bennett, T., Peripheral and autonomic nervous systems. In D.S. Farner, J.R. King and K.C. Parkes (Eds.), Avian 
Biology, Academic, New York, 1974, pp. 1-77.

12 Berrill, N.J., The development and growth of Ciona, J. Mar. Biol. Ass. U.K., 26 (1947) 616-625.

13 Blight, A.R., Golgi staining of 'primary' and 'secondary' motoneurons in the developing spinal cord of an amphibian, J. Comp. Neurol., 180 (1978) 679-689.

14 Bone, Q., The central nervous system in Amphioxus, $J$. Comp. Neurol., 115 (1960) 27-64.

15 Bone, Q., The central nervous system. In A. Brodal and R. Fänge (Eds.), The Biology of Myxine, Universitetsforlaget, Oslo, 1963, pp. 50-91.

16 Bone, Q., Some obserations upon the peripheral nervous system of the hagfish, Myxine glutinosa, J. Mar. Biol. Ass. U.K., 43 (1963) 31-47.

17 Bone, Q., Patterns of muscular innervation in the lower chordates, Int. Rev. Neurohiol, 6 (1964) 99-149.

18 Bone, Q., On the function of the two types of myotomal muscle fibre in elasmobranch fish, J. Mar. Biol. Ass. U.K., 46 (1966) 321-349.

19 Bone, Q., The dogfish neuromuscular junction: dual innervation of vertebrate striated muscle fibers?, J. Cell Sci., 10 (1972) 657-665.

20 Bone, Q., Locomotor muscle. In W.S. Hoar and D.J. Randall (Eds.), Fish Physiology, Vol. VII, Locomotion, Academic, New York, 1978, pp. 361-424.

21 Bone, Q. and Dana Ono, R., Systematic implications of innervation patterns in teleost myotomes, Breviora, 470 (1982) 1-23.

22 Bone, Q., Kiceniuk, J. and Jones, D.R., On the role of the different fibre types in fish myotomes at intermediate swimming speeds, Fish Bull., 76 (1978) 691-699.

23 Brichta, A. and Peterson, E.H., Organization of motor pools supplying cervical musculature in the rat, $\mathrm{Soc}$. $\mathrm{Neu}$ rosci. Abstr., 8 (1982) 876.

24 Brink, E.E., Morrell, J.I. and Pfaff, D.W., Localization of lumbar epaxial moto-neurons in the rat, Brain Res., 170 (1979) 23-41.

25 Brink, E.E. and Pfaff, D.W., Vertebral muscles of the back and tail of the albino rat (Rattus norvegicus albinus), Brain Behav. Evol., 17 (1980) 1-47.

26 Buchanan, J.T. and Cohen, A.H., Activities of identified interneurons, motoneurons, and muscle fibers during fictive swimming in the lamprey and effects of reticulospinal and dorsal cell stimulation, J. Neurophysiol., 47 (1982) 948-960.

27 Burkc, R.E., Motor units: anatomy, physiology and functional organization. In V.B. Brooks (Ed.), Handbook of Physiology, Section I, The Nervous System, Vol. II, Motor Systems, American Physiological Society, Washington, 1981, pp. 354-422.

28 Carlson, H., Halbertsma, J. and Zomlefer, M., Control of the trunk during walking in the cat, Acta Physiol. Scand., 105 (1979) 251-253.

29 Celio, M.R., Gray, E.G. and Yasargil, G.M., Ultrastructure of the Mauthner axon collateral and its synapses in the goldfish spinal cord, J. Neurocytol., 8 (1979) 19-29.

30 Chamberlain, F.W., Atlus of Avian Anatomy, Hallenbeck Printing Co., Lansing, 1943.

31 Chevallier, A., Role of somitic mesoderm in the development of the thorax in bird embryos. II. Origin of thoracic and appendicular musculature, J. Embryol. Exp. Morphol., 49 (1979) 73-88.

32 Chibuzo, G.A. and Cummings, J.F., An enzyme tracer study of the organization of the somatic motor center for the innervation of different muscles of the tongue: evidence for two sources, J. Comp. Neurol, 205 (1982) 273-281.

33 Cliff, G.F. and Ridge, R.M.A.P., Innervation of extrafusal and intrafusal fibres in snake muscle, J. Physiol. (London), 233 (1973) 1-18.

34 Coghill, G.E., The primary ventral roots and somatic motor column of Amblystoma, J. Comp. Neurol., 23 (1913) 121-143.

35 Coghill, G.E., Correlated anatomical and physiological studies of the growth of the nervous system in amphibia. VI. The mechanism of integration in Amblystoma punctatum, J. Comp. Neurol., 41 (1926) 95-152.

36 Denizot, J.P., Libouban, S. and Szabo, T., Anatomical study and HRP identification of electromotoneurons and motoneurons in the spinal cord of Gymnarchus niloticus, Exp. Brain Res., 53 (1983) 99-108.

37 Diamond, J., The Mauthner cell. In W.S. Hoar and D.J. Randall (Eds.), Fish Physiology, Vol. V, Academic, New York, 1971, pp. 265-346.

38 Diamond, J. and Yasargil, G.M., Synaptic function in the fish spinal cord: dendritic integration. In K. Akert and P.G. Waser (Eds.), Progress in Brain Research, Vol. 31, Mechanisms of Synaptic Transmission, Elsevier, New York, 1969, pp. 201-209.

39 Droge, M.H. and Leonard, R.B., Organization of spinal motor nuclei in the stingray, Dasyatis sabina, Brain Res., 276 (1983) 201-211.

40 Easter Jr., S.S., The growth and development of the superior oblique muscle and trochlear nerve in juvenile and adult goldfish, Anat. Rec., 195 (1979) 683-697.

41 Easter Jr., S.S., An oregonian school of zebra fish, TINS, 9 (1986) 246-248.

42 Eisen, J.S., Myers, P.Z. and Westerfield, M., Segmentally specific growth of motor axons in live zebrafish em. bryos, Soc. Neurosci. Abstr., 10 (1984) 371.

43 English, A.W., The functions of the lumbar spine during stepping in the cat, J. Morphol., 165 (1980) 55-66.

44 Erulkar, S.D. and Soller, R.W., Interactions among lumbar motoneurons on opposite sides of the frog spinal cord: morphological and electrophysiological studies, J. Comp. Neurol., 192 (1980) 473-488.

45 Feng, A.S., Neck muscles innervation patterns in the northern leopard frog (Rana p. pipiens), Neurosci. Lett., 29 (1982) 19-23.

46 Fetcho, J.R., The organization of the motoneurons innervating the axial musculature of vertebrates. I. Goldfish (Carassius auratus) and mudpuppies (Necturus maculosus), J. Comp. Neurol., 249 (1986) 521-550.

47 Fetcho, J.R., The organization of the motoneurons innervating the axial musculature of vertebrates. II. Florida water snakes (Nerodia fasciata pictiventris), J. Comp. Neurol., 249 (1986) 551-563.

48 Fetcho, J.R. and Faber, D.S., Synaptic connections between the Mauthner axons and identified motoneurons and interneurons in the caudal spinal cord of goldfish, Soc. Neurosci. Abstr., 12 (1986) 790.

49 Flood, P.R., A peculiar mode of muscular innervation in Amphioxus. Light and electron microscopic studies of the so-called ventral roots, J. Comp. Neurol., 126 (1966) 181-218.

50 Flood, P.R., Structure of the segmental trunk musculature in Amphioxus with notes on the course and 'endings' of the so-called ventral root fibres, Zeitschr. Zellforsch., 84 
(1968) 389-416.

51 Flood, P.R. and Storm-Mathisen. J., A third type of muscle fibse in the parietal muscle of the Atlantic hagfish $M y x$ ine glutinosa (L.)?, Zeitschr. Zellforsch., 58 (1962) 638-640.

52 Forehand, C.J. and Farel, P.B., Spinal cord development in anuran larvae. I. Primary and secondary neurons, $J$. Comp. Neurol., 209 (1982) 386-394.

53 Forrester, T. and Schmidt, H., An electrophysiological investigation of the slow muscle fibre system in the frog rec tus abdominus muscle, J. Physiol. (London), 207 (1970) $477-491$

54 Gase, J.P., Axial musculature. In C. Gans and T.S. Parsons (Eds.), Biology of the Reptilia, Vol. 11. Academic. New York, 1981, pp. 355-435.

55 Goodrich. E.S., Studies on the Structure and Development of Vertebrates, Dover, New York. 1930.

56 Goodrich, E.S., On the spinal nerves of the Myxinoidea, Q.J. Microsc. Sci., 80 (1937) $153 \ldots 158$

57 Graf, W. and Baker, R., The vestibuloocular reflex of the adult flatfish. I. Oculomotor organization, J. Neurophysiol., 54 (1985) 887-899.

58 Grillner, S., Wallén, P.. McClellan, A., Sigvardt, K., Williams, T. and Feldman, J.. The neural generation of locomotion in the lamprey: an incomplete account. In A. Roberts and B.L. Roberts (Eds.), Neural Origin of Rhythmic Movements. Symposia of the Society for Experimental Biology No. XXXVII. Cambridge University Press, Cambridge, 1983, pp. 285-303

59 Guthe, K., Reptilian muscle: fine structure and physiological parameters. In C. Gans and T.S. Parsons (Eds.), Biology of the Reptilia, Vol. 11. Academic, New York, 1981.pp. 265-354

60 Hagiwara, S. and Takahashi, K., Resting and spike potentials of skeletal muscle fibres in salt-water elasmobranch and teleost fish. J. Physiol. (London), 190 (1967) 499-518.

61 Haller, H., Ueber das Centralnervensysten in besondere über des Rückenmarks von Orthagoriscus mola, Morphol. Jahrb., 17 (1892) 198-270.

62 Herrick. C.J. The cranial and first spinal nerves of Menidia; a contribution upon the nerve components of the bony fishes, J. Comp. Neurol., 9 (1899) 153-445.

63 Hess. A., Vertebrate slow muscle fibers, Physiol. Rev., 50 (1970) 40-62

64 Hollyday, M., Organization of motor pools in the chick lumbar lateral motor column. J. Comp. Neurol., 194 (1980) $143-170$.

65 Hudson, R.C.L., Polyneuronal innervation of the fast muscles of the marine teleost Cottus scorpius L., J. Exp. Biol., 50 (1969) 47-67.

66 Hudson, R.C.L., On the function of the white muscles in teleosts at intermediate swimming speeds, J. Exp. Biol., 58 (1973) 509-522.

67 Hughes, A., Studies in embryonic and larval developmen in amphibia. II. The spinal motor-root, J. Embryol. Exp. Morphol., 7 (1959) 128-145.

68 Jayne, B., Comparative morphology of the semispinalisspinalis muscle of snakes and correlations with locomotion and constriction, J. Morphol., 172 (1982) 83-96.

69 Johnston. I.A., Structure and function of fish muscles, Symp. Zool. Soc. Lond., 48 (1981) 71-113.

70 Johnston. I.A., Dynamic properties of fish muscle. In P.W Webh and D Weihs (Eds.). Fish Biomechanics,
Praeger Publishers, New York, 1983, pp. 37-67.

71 Johnston, I.A., Davison, W. and Goldspink, G.. Energy metabolism of carp swimming muscles, $J$. Comp. Physiol. 114 (1977) 203-216.

72 Johnston, I.A., Ward, P.S. and Goldspink, G.A., Studies on the swimming musculature of the rainbow trout. I. Fibre types, J. Fish Biol. . 7 (1975) 451-458.

73 Kaupp, R.F., The Anatomy of the Domestic Fowl. Saund. ers, Philadelphia, 1918.

74 Kolster, R.. Studien über das centrale Nervensystem. I. Uber das Rückenmark einiger Teleustier, Acia Soc. Sci. Fennicae, 24 (1898) 1-88.

75 Kusuma, A., ten Donkelaar. H.J. and Nieuwenhuys, R., Intrinsic organization of the spinal cord. In $C$. Gans, R.G., Nothcutt and P. Ulinski (Eds.), Biology of the Rep. tilia, Vol. 10. Neurology B. Academic. New York. 1979. pp. 59-109.

76 Landmesser, L., The distribution of motoneurones supplying chick hindlimb muscles, J. Physiol. (London), 284 (1978) 371-389.

77 Lee, M.T., Regeneration and functional reconnection of an identified vertebrate central neuron, J. Neurosci., 2 (1982) 1793-1811.

78 Leggissa, S. Le basi anatomiche nella evoluzione del "comportamento" durante lo sviluppo embrionale e postembrionale di Trota (Salmo fario, irideus e lacustris). Zeitschr. Anat. Entwicklungsgesch., 111 (1942) 601-675.

79 Leonard, R.B., Coggeshall, R.E. and Willis, W.D., A documentation of an age related increase in neuronal and axonal numbers in the stingray, Dasvatis sabina. Leseuer. J. Comp. Neurol., 79 (1978) 13-22

80 Lewis, P.R. and Hughes, A.F.W., Patterns of myo-neural junctions and cholinesterase activity in the muscles of tadpoles of Xenopus laevis, Q. J. Microsc. Sci., $101(1960)$ $55-67$

81 Martin, I.S. . Contribution a l'étude de la structure interne de la moelle épinière chez le poulet et chez la truite. Cellule, 11 (1895) 53-80

$82 \mathrm{McHanwell}, \mathrm{S}$. and Biscoe, T.J., The localization of motoneurons supplying the hindlimb muscles of the mouse, Philos. Trans. Roy. Soc. Lond., 293 (1981) 477-508

83 Mizuno. N., Konishi, A. and Sato, M.. Localization of masticatory motoneurons in the cat and rat by means of retrograde axonal transport of horseradish peroxidase, $J$. Comp. Neurol., 164 (1975) 105-116.

84 Moody, S.A. and Jacobson, M., Compartmental relationships between anuran primary motoneurons and somitic muscle fibers that they first innervate, $J$. Neurosci., 3 (1983) $1670-1682$

85 Morgan, D.L. and Proske, U. . Vertebrate slow muscle: its structure, pattern of innervation, and mechanical properties, Physiol. Rev., 64 (1984) 103-169.

$86 \mathrm{Mos}, \mathrm{W}$. and Williamson, R.. A quantitative analysis of the spinal motor pool and its target muscle during growth in the dogfish. Scyliorhinus canicula, J. Comp. Neurol., 248 (1986) 431-440.

87 Mosauer. W.. The myology of the trunk region of snakes and its significance for ophidian taxonomy and phylogeny, Publ. Univ. Calif. (Los Angeles). 1 (1935) 81-120.

88 Myers, P.Z., Morphology and development of motoneurons in the zebrafish spinal cord, Soc. Neurosci. Abstr., 9 (1983) 848 .

89 Myers, P.Z., Spinal motoneurons of the larval zebrafish, J. Comp. Neurol., 236 (1985) 555-561. 
90 Myers, P.Z., Eisen, J.S. and Westerfield, M., Development and axonal outgrowth of identified motoneurons in the zebrafish, J. Neurosci., 6 (1986) 2278-2289.

91 Nakao, T., Electron microscopic studies on the myotomes of larval lamprey, Lampetra japonica, Anat. Rec., 187 (1976) 383-403.

92 Nakao, T., An electron microscopic study of the neuromuscular junction in the myotome of larval lamprey, Lampetra japonica, J. Comp. Neurol., 165 (1976) 1-15.

93 Naylor, B.G. and Nussbaum, R.A., The trunk musculature of caecilians (Amphibia: Gymnophiona), J. Morphol., 166 (1980) 259-273.

94 Nishi, S., Zur vergleichenden Anatomie der eigentlichen (genuinen) Rückenmuskeln (Spino-dorsale Muskeln der tetrapoden Wirbeltiere), Morphol. Jahrb., 50 (1916) 167-318.

95 Nishi, S., Muskeln des Rumfes. In L. Bolk, E. Göppert, E. Kallius and W. Lubosch (Eds.), Handbuch der vergleichenden Anatomie der Wirbeltiere, Urban and Schwarzenberg, Berlin/Wien, 1938, 351-446.

96 Noden, D.M., The embryonic origins of avian cephalic and cervical muscles and associated connective tissues, Am. J. Anat., 168 (1983) 257-276.

97 Nordlander, K.H., Developing descending neurons of the early Xenopus tail spinal cord in the caudal spinal cord of early Xenopus, J. Comp. Neurol., 228 (1984) 117-128.

98 Nordlander, R.H., Motoneurons of the tail of young $\mathrm{Xe}$ nopus tadpoles, J. Comp. Neurol., 253 (1986) 403-413.

99 Northcutt, R.G., The comparative anatomy of the nervous system and the sense organs. In M.H. Wake (Ed.), Hyman's Comparative Vertebrate Anatomy, University of Chicago Press, Chicago, 1979, pp. 615-769.

100 Ono, R.D., Dual motor innervation in the axial musculature of fishes, J. Fish Biol., 22 (1982) 395-408.

101 Pasaro, R., Torres, B. and Delgado-Garcia, J.M., Location of short neck muscle motoneurons in the cat as revealed by horseradish peroxidase, Neurosci. Lett., 43 (1983) 131-135.

102 Peters, A., The peripheral nervous system. In A. Brodal and R. Fange (Eds.), The Biology of Myxine, Universitetsforlaget, Oslo, 1963, 92-123.

103 Peters, A. and Mackay, B., The structure and innervation of the myotomes of the lamprey, J. Anat., 95 (1961) 575-585.

104 Radinsky, L., The comparative anatomy of the muscular system. In M.H. Wake (Ed.), Hyman's Comparative Vertebrate Anatomy, University of Chicago Press, Chicago, 1979, pp. 327-377.

105 Raynaud, A.P., Clairambault, P., Renous, S. and Gasc, J.P., Organization des cornes ventrales de la moelle épinière, dans les régions brachiale et lombaire, chez les embrions de reptiles serpentiformes et de reptiles à membres bien développés, C.R. Acad. Sci. Paris. Ser. D., 285 (1977) 1507-1509.

106 Rayner, M.D. and Keenan, M.J., Role of red and white muscles in the swimming of the skipjack tuna, Nature (London), 214 (1967) 392-393.

107 Richmond, F.J., Scott, D.A. and Abrahams, V.C., Distribution of motoneurons to neck muscles, biventer cervicis, splenius and complexus in cat, J. Comp. Neurol., 181 (1978) 451-463.

108 Ridge, R.M.A.P., Different types of extrafusal muscle fibers in snake costocutaneous 'muscles, J. Physiol. (London), 217 (1971) 393-418.
109 Roberts, A. and Clarke, J.D.W., The neuroanatomy of an amphibian embryo spinal cord, Philos. Trans. Roy. Soc. London, B296 (1982) 195-212.

110 Roberts, B.L., Spontaneous rhythms in the motoneurons of spinal dogfish (Scyliorhinus canicula), J. Mar. Biol. Ass. U.K., 49 (1969) 33-49.

111 Roberts, B.L., The spinal nerves of the dogfish (Scyliorhinus), J. Mar. Biol. Ass. U.K., 49 (1969) 51-75.

112 Roberts, B.L. and Williamson, R.M., Motor pattern formation in the dogfish spinal cord. In A. Roberts and B.L. Roberts (Eds.), Neural Origin of Rhythmic Movements, Symp. Soc. Exp. Biol., No. XXXVII, Cambridge University Press, Cambridge, 1983, pp. 331-350.

113 Romer, A.S. and Parsons, T.S., The Vertebrate Body, Saunders, Philadelphia, 1977.

114 Rovainen, C.M., Neurobiology of lampreys, Physiol. Rev., 59 (1979) 1007-1077.

115 Rovainen, C.M., Identified neurons in the lamprey spinal cord and their roles in fictive swimming. In A. Roberts and B.L. Roberts (Eds.), Neural Origin of Rhythmic Movements, Symp. Soc. Exp. Biol., No. XXXVII, Cambridge University Press, Cambridge, 1983, pp. 305-330.

116 Rovainen, C.M. and Dill, D.A., Counts of axons in electron microscopic sections of ventral roots in lampreys, $J$. Comp. Neurol., 225 (1984) 433-440.

117 Ruigrok, T.J.H., Crowe, A. and Ten Donkelaar, H.J., The distribution of motoneurons innervating hindlimb muscles in the terrapin Pseudemys scripta elegans, Neurosci. Lett., 28 (1982) 157-162.

118 Sasaki, F., Histochemical and ultrastructural studies of tail muscles in the anuran tadpole, Acta Histochem. Cytochem., 7 (1974) 239-256.

119 Sasaki, F., Histochemical and biochemical investigation of the tail muscle of anuran tadpoles during metamorphosis, Acta Histochem. Cytochem., 10 (1977) 413-425.

120 Scanlon, T.C., Anatomy of the Neck of the Western Painted Turtle (Chrysemys picta belli Gray: Reptilia, Testudinata) from the Perspective of Possible Movements in the Region, Ph.D. Thesis, University of Michigan, 1982.

121 Scherer, S.S., Reinnervation of the extraocular muscles in goldfish is nonselective, $J$. Neurosci., 6 (1986) 764-773.

122 Schnitzlein, H.N. and Brown, H.K., Spinal motoneurons of the goldfish (Carassius auratus), Brain Behav. Evol., 12 (1975) 207-228.

123 Schroder, H.D., Organization of the motoneurons innervating the pelvic muscles of the male rat, J. Comp. Neurol., 192 (1980) 567-587.

124 Shufeldt, R.W., The Myology of the Raven (Corvus corax sinuatus). A Guide to the Study of the Muscular System in Birds, Macmillan, London, 1980

125 Smith, C.L. and Hollyday, M., The development and postnatal organization of motor nuclei in the rat thoracic spinal cord, J. Comp. Neurol., 220 (1983) 16-28.

126 Sprague, J.M., Motor and propriospinal cells in the thoracic and lumbar ventral horn of the rhesus monkey, $J$. Comp. Neurol., 95 (1951) 105-123.

127 Stickland, N.C., Growth and development of muscle fibres in the rainbow trout (Salmo gairdneri), J. Anat., 137 (1983) 323-333.

128 Stillhard, G., Musculi longus capitis et splenius der Ratte und inncrvierende Motoneurone, Acta. Neuropathol. (Berlin), 53 (1981) 267-274

129 Straznicky, C. and Tay, D., The localization of motoneuron pools innervating wing muscles in the chick, Anat. 
Embryol., 166 (1983) 209-218.

130 Szekely, G. and Cheh, G., Organization of locomotion. In R. Llinás and W. Precht (Eds.), Frog Neurobiology, Springer, Berlin, 1976, pp. 765-792.

131 Takeuchi, A., Neuromuscular transmission of fish skeletal muscles investigated with intracellular microelectrodes, $J$. Cell Comp. Physiol. 54 (1959) 211-220.

132 Teravainen, H., Anatomical and physiological studies on muscles of lamprey, J. Neurophysiol., 34 (1971) 954-973.

133 Teravainen, H. and Rovainen, C.M., Fast and slow motoneurons to body muscle of the sea lamprey, $J$. Neurophysiol., 34 (1971) 990-998.

134 Teravainen, H. and Rovainen, C.M., Electrical activity of myotomal muscle fibers, motoneurons, and sensory dorsal cells during spinal reflexes in lampreys, J. Neurophysiol., 34 (1971) 999-1009.

135 Thorstensson, A., Carlson, H., Zomlefer, M.R. and Nilsson, J., Lumbar back muscle activity in relation to trunk movements during locomotion in man, Acta Physiol. Scand., 116 (1982) 13-20.

136 Totland, G.K., Three muscle fibre types in the axial muscle of axolotl (Ambystoma mexicanum Shaw). A quantitative light- and electron microscopic study, Cell Tissue Res., 168 (1976) 65-78.

137 Totland, G.K., Histological and histochemical studies of segmental muscle in the axolotl Ambystoma mexicanum Shaw (Amphibia: Urodela), Now. J. Zool., 24 (1976) 79-90.

138 Van der Horst, C.I., Spinalnerven. In L. Bolk, E. Göppert, E. Kallius and W. Lubosch (Eds.), Handbuch der vergleichenden Anatomie der Wirbeltiere, Urban and Schwarzenberg, Berlin, 1934, pp. 505-540.

139 Van Gehuchten, A., La moelle épinière de la truite (Trutta fario), Cellule, 11 (1895) 111-173.

140 Van Mier, P., van Rheden, R. and ten Donkelaar, H.J., The development of the dendritic organization of primary and secondary motoneurons in the spinal cord of Xenopus laevis. An HRP study, Anat. Embryol., 172 (1985) 311-324.

141 Van Raamsdonk, W., Mos, W., Smit-Onel, M.J., van der Laarse, W.J. and Fehres, R., The development of the spinal motor column in relation to the myotomal muscle fibres in the zebrafish (Brachydanio rerio). I. Posthatching development, Anat. Embryol., 167 (1983) 125-139.

142 Wake, M., Spinal nerve distribution in caecilians: (Amphibia: Gymnophiona), Am. Sac. Zool. Abstr., 24 (1984) $48 \mathrm{~A}$.

143 Wallén, P., Grillner, S., Feldman, J.C. and Bergelt, S., Dorsal and ventral myotome motoneurons and their input during fictive locomotion in lamprey, J. Neurosci, 5 (1985) 654-661.

144 Watanabe, K., Sasaki, F., Takahama, H. and Iseki, H., Histogenesis and distribution of red and white muscle fibers of urodelan larvae, J. Anat., 130 (1980) 83-96.

145 Westerfield, M., Myers, P.Z. and Eisen, J.S., Polyneuro- nal and intersegmental innervation of body muscles in the zebrafish, Soc. Neurosci. Abstr., 10 (1984) 371

146 Westerfield, M. and Eisen, J.S., The growth of motor axons in Xenopus spinal cord, Soc. Neurosci. Abstr., 9 (1983) 210

147 Westerfield, M. and Eisen, J.S., The growth of motor axons in the spinal cord of Xenopus embryos, Dev. Biol., 109 (1985) $96-101$

148 Westerfield, M., McMurrary, J.V. and Eisen, J.S., Identified motoneurons and their innervation of axial muscles in the zebrafish, $J$. Neurosci., $6(1986)$ 2267-2277.

149 Whiting, H.P., Nervous structure of the spinal cord of the young larval brook-lamprey, Q.J. Microsc. Sci., 89 (1948) 359-384.

150 Whiting, H.P., Mauthner neurones in young larval lampreys (Lampetra spp.). Q. J. Microsc. Sci.. 98 (1957) $163-178$.

151 Wild, J.M. and Zeigler, H.P., Central representation and somatotopic organization of the jaw muscles within the facial and trigeminal nuclei of the pigeon (Columba liva), $J$. Comp. Neurol., 192 (1980) 175-201.

152 Wilkinson, R.S. and Lichtman, J.W., Kegular alternation of fiber types in the transversus abdominus muscle of the garter snake, J. Neurosci., 5 (1985) 2979-2988.

153 Willemse, J.J., Arrangements of connective tissue fibres and muscle fibres in the tail musculature of adult newts, $Z$. Morphol. Tiere, 77 (1974) 255-269.

154 Willemse, J.J. and van den Berg, P.G., Growth of striated muscle fibres in the M. lateralis of the European eel $A n$ guilla anguilla (L.) (Pisces, Teleostei), J. Anat., 125 (1978) 447-466.

155 Yasargil, G.M. and Diamond, J., Startle-response in teleost fish: an elementary circuit for neural discrimination, Nature (London), 220 (1968) 241-243.

156 Yeow, M.B.L. and Peterson, F.H., Organization of motor pools supplying the cervical musculature in a cryptodyran turtle, Pseudemys scripta elegans. I. Dorsal and ventral motor nuclei of the cervical spinal cord and muscles supplied by a single motor nucleus, J. Comp. Neurol., 243 (1986) 145-165.

157 Yeow, M.B.L. and Peterson, E.H., Organization of motor pools supplying the cervical musculature in a cryptodyran turtle, Pseudemys scripta elegans. II. Medial motor nucleus and muscles supplied by two motor nuclei, J. Comp. Neurol., 243 (1986) 166-181.

158 Youngstrom, K.A., Studies on the developing behavior of Anura, J. Comp. Neurol., 68 (1938) 351-379.

159 Youngstrom, K.A., A primary and a secondary somatic motor innervation in Amblystoma, J. Comp. Neurol., 73 (1940) 139-151.

160 Zomlefer, M.R., Provencher, J., Blanchette, G. and Rossignol, S., Electromyographic study of lumbar back muscles during locomotion in acute high decerebrate and in low spinal cats, Brain Res., 290 (1984) 249-260. 